DOES BEING REAL PAY OFF? EXAMINING THE IMPACT OF PERCEIVED

\title{
AUTHENTICITY IN CRISIS COMMUNICATION
}

\begin{tabular}{c} 
A Dissertation \\
Presented to \\
The Faculty of the Graduate School \\
At the University of Missouri \\
\hline
\end{tabular}

In Partial Fulfillment

Of the Requirements for the Degree

Doctor of Philosophy

By

MIKKEL SOELBERG CHRISTENSEN

Dr. Glen T. Cameron, Dissertation Supervisor

MAY 2019 
The undersigned, appointed by the dean of the Graduate School, have examined the dissertation entitled

\section{DOES BEING REAL PAY OFF? EXAMINING THE IMPACT OF PERCEIVED AUTHENTICITY IN CRISIS COMMUNICATION}

presented by Mikkel Soelberg Christensen, a candidate for the degree of doctor of philosophy, and hereby certify that, in their opinion, it is worthy of acceptance.

Dr. Glen Cameron

Dr. Fritz Cropp

Dr. Margaret Duffy

Dr. J. Brian Houston

Dr. Ben Warner 


\section{DEDICATION}

To Niels Christensen (1945 - 2018). My best friend, hero, and dad. Without your love and support, this dissertation would not have been possible. You are dearly missed. 


\section{ACKNOWLEDGEMENT}

The journey to a Ph.D. has been long and challenging, and I would not have made it this far without the backing of these tremendous people in my life. First and foremost, I need to thank my fiancée Katie. You have been my rock through every challenge, and I'm so incredibly grateful that you are by my side. A special thank you should also go to my family. Your love and support mean the world to me, and I appreciate you helping me whole-hearted through every step of this endeavor.

Of course, none of this would have been possible without my outstanding advisor, Dr. Glen Cameron. You have not only been my academic mentor but also gave me invaluable support and advice when life was most challenging. For that, I will always be grateful, and you are indeed an inspiration! I also want to thank my fantastic committee members Dr. Margaret Duffy, Dr. Fritz Cropp, Dr. Brian Houston, and Dr. Ben Warner for your guidance, for pushing me, for introducing me to new perspectives, and for simply being inspirational mentors I can look up to.

I hold special gratitude to my friends and colleagues in the $\mathrm{Ph}$. D. program who helped make this experience such an enjoyable journey, despite the tests we had to go through. I also owe a big thank you to Richard Møller Nielsen for showing me that anything is possible with the right attitude and a bit of luck. To my students and colleagues at Stephens College for inspiring me. And last, but not least, to Dr. Joy Jenkins and Rev. Hank Jenkins for being the best friends anyone could ask for. 


\section{TABLE OF CONTENTS}

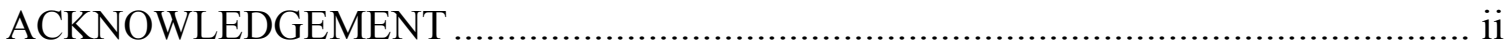

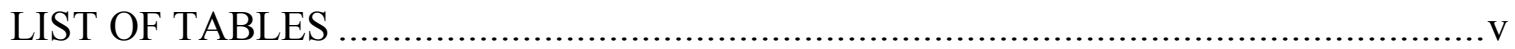

LIST OF FIGURES ..................................................................................

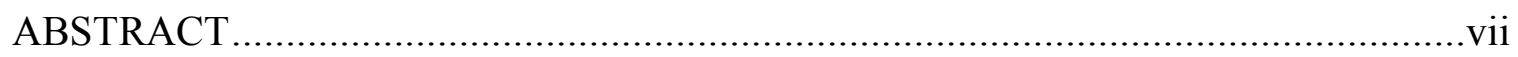

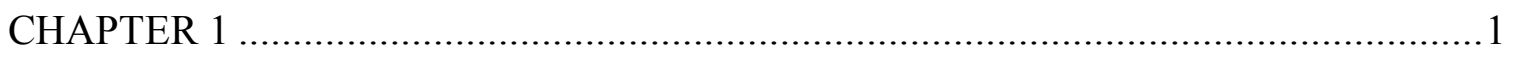

INTRODUCTION ......................................................................................... 1

CHAPTER 2 - LITERATURE REVIEW ..............................................................

Crisis Communication .................................................................................

Contingency Theory of Accommodation ....................................................... 8

Situational Crisis Communication Theory.......................................................... 12

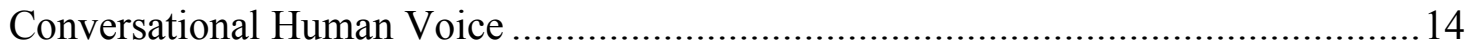

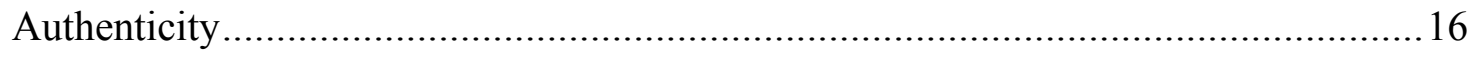

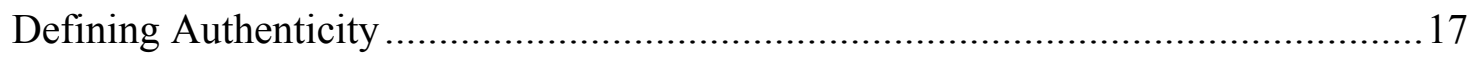

The Anti-commercial Aspect of Authenticity......................................................22

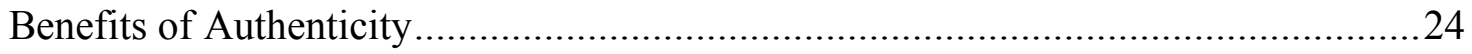

CHAPTER 3 - HYPOTHESES AND RESEACH QUESTIONS ..............................27

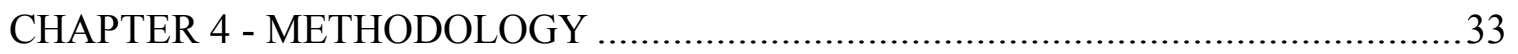

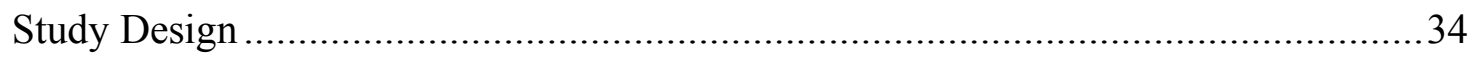

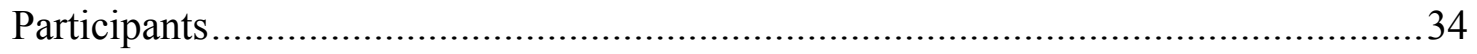


Stimuli Development and Manipulation. 36

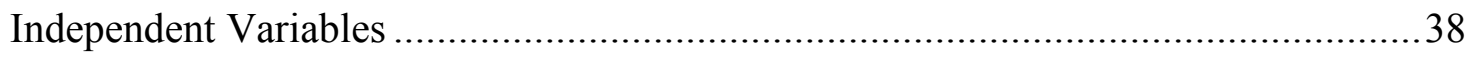

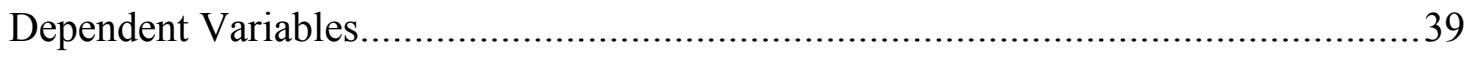

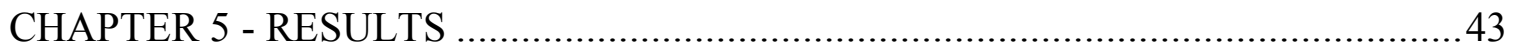

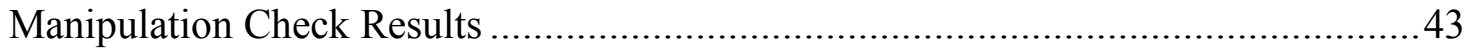

Tests of Hypotheses and Research Questions ...................................................45

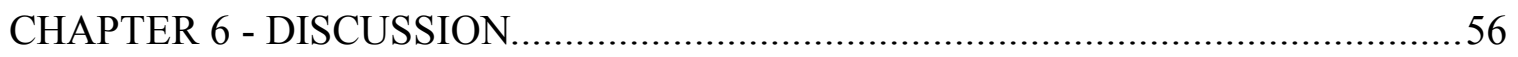

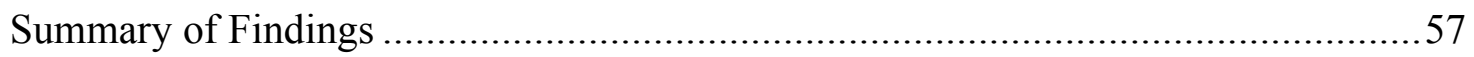

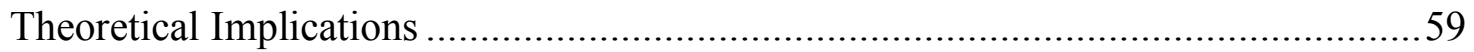

Authenticity and the Contingency Theory of Accommodation ................................63

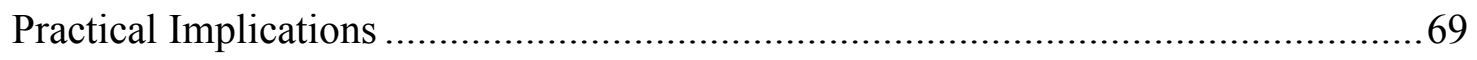

Limitations and Future Research........................................................ 70

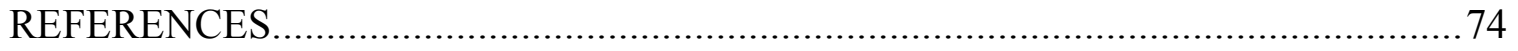

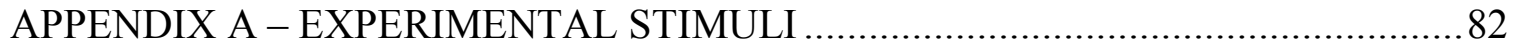

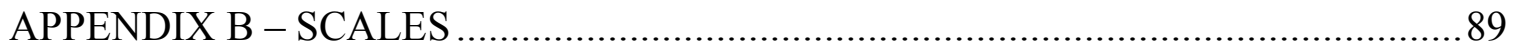

APPENDIX C - MAIN STUDY INSTRUMENT ................................................. 91

VITA 


\section{LIST OF TABLES}

Table 3. 1. Summary of Theory, Hypotheses, and Research Purposes ...........................32

Table 5. 1. Means of Authenticity Scores by Message Type .......................................44

Table 5. 2. Mean of Accommodation Scores by Response Type ..................................45

Table 5. 3. Means of Crisis Responsibility Attribution by Message and Response Type 47

Table 5.4. Means of Organizational Reputation by Message and Response Type..........49

Table 5. 5. Means of Anger by Message and Response Type ........................................52

Table 5. 6. Means of WOM-Intention by Message and Response Type........................55 


\section{LIST OF FIGURES}

Figure 5. 1. An Interaction Effect Between Authenticity and Accommodation on Crisis

Responsibility Attribution in the Red Cross Scenario. 46

Figure 5.2. An Interaction Effect Between Authenticity and Accommodation on Crisis

Responsibility Attribution in the Red Cross Scenario.

Figure 5.3. An Interaction Effect Between Authenticity and Accommodation on Organizational

Reputation in the Red Cross Scenario .48

Figure 5.4. An Interaction Effect Between Authenticity and Accommodation on Organizational Reputation in the United Airlines Scenario

Figure 5.5 An Interaction Effect Between Authenticity and Accommodation on Anger in the Red

Cross Scenario. .51

Figure 5.6. An Interaction Effect Between Authenticity and Accommodation on Anger in the

United Airlines Scenario. .52

Figure 5.7. An Interaction Effect Between Authenticity and Accommodation on WOM-intention in the Red Cross Scenario. .54

Figure 5.8. An Interaction Effect Between Authenticity and Accommodation on WOM-Intention in the United Airlines Scenario. 55 


\title{
DOES BEING REAL PAY OFF? EXAMINING THE IMPACT OF PERCEIVED AUTHENTICITY IN CRISIS COMMUNICATION
}

\author{
Mikkel Soelberg Christensen \\ Dr. Glen T. Cameron, Dissertation Supervisor
}

\begin{abstract}
This study examines whether communicating with authenticity in a crisis situation can help produce more successful post-crisis results and if the type of crisis apology impacts the relationship between authenticity and post-crisis success. The theoretical framework is centered around the contingency theory of accommodation, the situational crisis communications theory, and findings from other fields on the impact of authenticity. Authenticity is hypothesized to have a positive effect on post-crisis outcomes, and it is also explored if there is an interaction effect between authenticity and degree of accommodation.
\end{abstract}

The study uses a 2 (authenticity: present vs. not present) $\times 2$ (type of crisis response: accommodative vs. advocating) mixed experimental design, where authenticity and type of crisis response both are between-subjects factors. For the experiment, 229 participants were presented with modified crisis scenarios and manipulated responses in an online setting and subsequently asked about how the organization handled the crisis. The experiment was repeated in two different scenarios focusing on the American Red Cross and United Airlines.

The findings show that authentic crisis responses lead to significantly more positive crisis outcomes, measured on four different parameters than non-authentic crisis responses did. 
Whether an organization accommodated or not in their crisis response did not significantly impact the crisis outcomes, and the study also failed to find any interaction between authenticity and accommodation on crisis success. 


\section{CHAPTER 1}

\section{INTRODUCTION}

Authenticity has become a key concept for both public relations scholars and practitioners in recent years, and the demands for more knowledge of authenticity appears only to be increasing (Lehman, O’Connor, Kovacs, \& Newman, 2019; Sisson \& Bowen, 2017). Authenticity is now a core organizational value (Bowen, 2010), and the hallmark of an excellent organizational-public relationship (Brønn, 2010), and organizations have understood that they need to invest significantly in getting authenticity right, as it can gain them loyal and trusting audiences Edwards (2010) argues.

Authenticity is far from a new concept, as its roots can be traced back to ancient Greece (Shen \& Kim, 2012), but in recent years, it has gotten extra attention from strategic communications scholars and practitioners alike. Globalization and the prominence of social media have led to a higher demand for, and focus on, transparency, visibility, and accountability among increasingly aware and active publics (Mazzei, Lee, Togna, \& Kim, 2016). This has, in turn, increased the demand for perceived authenticity in organizational communication (McDonald, 2016; Molleda \& Jain, 2013; Shen \& Kim, 2012). With an overload of questionable information to sort through for online consumers, communication that is perceived as authentic becomes a rare and highly valued commodity (Molleda, 2009), so for organizations that want to communicate successfully on social media, authenticity is no longer an option, but a necessity, Men, and Tsai (2016) argue. Potter even declared that "the demand for authenticity...is one of the most powerful movements in contemporary life" (2011, p. i), and authenticity is now at the 
very core of the public relations and strategic communications industry Henderson and Bowley (2010) argue.

Cook (2007) foresaw this development a decade ago when he was writing about the future trends in strategic communication in a magazine for practitioners: "We're at the start of an era where people want authentic stories about authentic people. PR professionals are the storytellers. It's our job to help find the authenticity at the core of our companies and clients, and to tell those stories to the world in words that will truly be heard." (Cook, 2007, p. 33). Gilmore and Pine even went one step further and declared authenticity the most important communication trend driven by social media in the $21^{\text {st }}$ century (2007), and the Arthur W. Page Society (2007) asserted that: "Authenticity will be the coin of the realm for successful corporations and for those who lead them" (p. 6).

Public relations practitioners have also found that being authentic is crucial to get continued loyalty from fickle audiences (Deibert, 2019), and it appears to be a substantial area of focus across the industry. For FleishmanHillard, one of the world's biggest public relations firms, the focus on authentic communication is so great that they annually conduct research on the "authenticity gap" to measure the difference between stakeholders' expectations of organizations and their actual experiences (FleishmanHillard, 2015) referred by Graves (2015).

It is not without reason that there has been an increasing focus on authenticity, as it has been proven to create positive communication outcomes in a wide range of organizational communications settings, such as psychology, interpersonal communication, tourism, luxury branding, and strategic communication.

However, so far, the research that has been done testing whether authenticity also has a positive effect when applied in a crisis communication setting is minimal. There is only 
anecdotal evidence revealing that authentic communication is effective in limiting reputational damage from an organizational crisis (Mazzei et al., 2016) and that an organization that already is perceived as authentic will be less vulnerable during a reputational crisis (Sisson \& Bowen, 2017). This is even though crisis communication is one of the most prominent topics of the public relations literature (Ki \& Khang, 2005), and an area where communicators can make the most significant difference (Fearn-Banks, 2017).

A multitude of crisis communication theories can help guide practitioners and scholars on the most effective response strategies when navigating a reputational crisis. The contingency theory of accommodation (Cancel, Cameron, Sallot, \& Mitrook, 1997; Cancel, Mitrook, \& Cameron, 1999), helps crisis managers decide what to do in a crisis situation. Based on groups external and internal variables, the theory indicates whether the crisis managers should stand their ground and not give in to public pressure, or if they should accommodate to publics, for example by apologizing and changing their ways. The situational crisis communication theory (Coombs, 2007) identifies three clusters of crises and suggests that crisis managers should match strategic crisis responses to the level of crisis responsibility and the reputational threat that is posed by a crisis. Both of these theories are well tested and provide reliable guidance for crisis practitioners, but they do not offer any guidance for when or how authenticity can be used in a crisis response.

The purpose of this study is to rectify this gap in the literature, through a theoretical framework incorporating the contingency theory of accommodation, the situational crisis communication theory and authenticity theory. This will be tested in experiments evaluating the impact of crisis responses containing authentic language compared to crisis responses with nonauthentic language, on post-crisis success. Furthermore, it will also be tested whether authentic 
responses are more effective when given as part of an accommodating or advocating crisis response.

The rest of this study will be as follows. Chapter two contains a literature review, that covers the most relevant scholarship on crisis communication, the contingency theory of accommodation, the situational crisis communication theory, and authenticity is reviewed, and a definition of authenticity is presented. Chapter three presents the hypotheses and research questions, and the theoretical foundations of them. Chapter four introduces the methodology for the study, a 2 (authentic vs. not authentic) by 2 (accommodating vs. not accommodating) between subjects experimental design tested in two separate crisis scenarios. Chapter five contains the findings for the study. Chapter six discusses the practical and theoretical implications of the findings. And finally, chapter seven contains a brief conclusion of the study. 


\section{CHAPTER 2}

\section{LITERATURE REVIEW}

It has been generally accepted by both practitioners and scholars of public relations going back as far as the 1950s that effective organizational communication during crisis situations is of the utmost importance, since a crisis that is not addressed in the most appropriate way, can have a devastating impact on an organization's reputation to such a severe degree, that it might not be possible to recover (Coombs, 2014; Fearn-Banks, 2017).

However, it is only in the last few decades that the study of crisis communication really developed from a methodological perspective (Avery, Lariscy, Kim, \& Hocke, 2010). These developments have helped bridge the gaps between academics and crisis practitioners to some degree, but as this literature review will reveal, there are still some questions left unanswered. One of those gaps is the connection between authentic communication and crisis communication outcomes. Authenticity has been shown to lead to positive communications in a broad range of communication contexts, but the impact it has on crisis communication is yet to be tested empirically.

\section{Crisis Communication}

As the study of crisis communication has grown among public relations scholars, considerable attention has been dedicated to the question of how a crisis should be defined. Fearn-Banks (2017) defines a crisis as anything that interrupts the normal flow of business, and she argues that it can range from events that leave minimal damage to the organization's reputation and profit to events that have significant effects on the organization, the industry, the 
stakeholders, and threaten the survival of the firm. Seeger, Sellnow, and Ulmer argue that a crisis can be an event that causes high levels uncertainty and is "perceived to threaten an organization's high priority goals" (1998, p. 233). Coombs goes one step further and defines a crisis as "the perception of an unpredictable event that threatens important expectancies of stakeholders and can seriously impact an organization's performance and generate negative outcomes" (2007, pp. 2-3). The latter two these definitions touch on the perceptive nature of the crisis, something that is a key component of most definitions in the literature. A crisis does not exist if stakeholders don't perceive it, and, conversely, if the stakeholders perceive an event as a crisis, then it exists (Coombs \& Holladay, 2011).

While some refer to a crisis and problem interchangeably, it is important to note that there is a distinction between a reputational crisis and a reputational problem. This distinction presents itself it two ways: a reputational crisis is the consequence of a "specific critical incident, a reputational problem is more likely to be caused by an ongoing weakness or shortcoming." (Sohn \& Lariscy, 2014), and a crisis is different from a problem in its "magnitude and scope" (B. K. Lee, 2005). Similarly, when describing crisis situations, some, both scholars, practitioners, and media outlets, appear to use the terms "disaster" and "crisis" synonymously, but in most of the crisis communication literature the two concepts are treated separately, with distinctions focused around the reality of an event versus the perceived threat of a situation. Boin, Hart and Kuipers defined a disaster as "an event that causes human suffering and infrastructural damage." (2018, p. 24) and which often includes natural disasters such as hurricanes, earthquakes, and floods, but also man-made events such as terrorism, a breakdown of the economy, technological failures, and the consequences of war such as mass migration and famine. A crisis, on the other hand, they define as "a threat that is perceived to be existential in one way or another" (Boin et 
al., 2018, p. 25), but it is a threat that hasn't been realized yet, and therefore still allows the stakeholders to take action to avoid or minimize the potential damage.

If an organization is to navigate through a reputational crisis with the least amount of damage to its image, effective crisis communication is crucial. The purpose of crisis communication is "to prevent or lessen the negative outcomes of a crisis and thereby protect the organization, stakeholders, and industry from harm"' (Coombs, 2007, p. 5). Heath and Palenchar expand on this and define crisis communication as "the enactment of the narrative of control (or at least its appearance) in the face of high uncertainty in an effort to win external audiences' confidence in ways that are ethical"' (2008, p. 295).

Discussions of crisis communication in both scholarly literature and among practitioners are founded on the underlying assumption that an organization's success during a crisis is contingent on selecting the most appropriate crisis response strategy and by how successful they are in implementing it (Park, 2011). By applying a crisis response strategy in an effective manner, an organization can diminish, or in some cases, completely eliminate the potential damage to its reputation, and also impact how its publics perceive and interpret the situation (Cancel et al., 1997; Coombs, 2007; Betty Kaman Lee, 2004).

Pearson and Clair (1998) argue that crisis management efforts can be determined to have been effective when an organization's operations are sustained or resumed, for example if the organization is able to maintain or regain the momentum of core activities necessary for transforming input to output at levels that satisfy the needs of key customers, if organizational and external stakeholder losses are minimized, and if learning occurs, so lessons are transferred to future incidents. However, this is far from the only approach to evaluating the impact of successful crisis communication. Successful crisis responses have also been operationalized as 
(lack of) responsibility assigned by key audiences, perceived levels of corporate responsibility and lack of affect/ anger. These will all be described in further details in the methodology chapter.

\section{Contingency Theory of Accommodation}

One of the most prominent theories of strategic communication is the Contingency Theory of Accommodation (Cameron, Cropp, \& Reber, 2001; Cancel, Cameron, Sallot, \& Mitrook, 1997; Cancel, Mitrook, \& Cameron, 1999). The authors argue that true excellence in crisis communication consists of finding the perfect spot on the continuum between accommodation and advocacy. In this context, accommodation refers to being as compliant as possible in the crisis response. For example, by giving an apology, taking the necessary steps to prevent it from happening again, and by pledging money to fix the damage that others were exposed to as a result of the crisis. Advocacy, on the other hand, refers to sticking with the organization's original stance and not providing accommodation to the public's demands, even despite the pressure. For example, by refusing to admit to any wrongdoing, refusing to take action, and reinforcing their stance.

The contingency theory of accommodation helps us understand the dimensions that affect the stances of organizations, and it also functions as a guide for practitioners. The authors, in

their original paper, identify 87 factors that decide where on the continuum a stance in a given situation should be. The factors are divided into two main groups: internal and external. The external variables are furthermore clustered in the following five groups: Threats, such as pending litigation, government regulation, damaging publicity to the organization's reputation and legitimizing activists' claims. The industry-specific environment, such as the number of 
competitors and the levels of competition. The general political/social environment, such as the degree of political and social support for the organization, external public characteristics, and the issue under consideration (Cameron, Wilcox, Reber, \& Shin, 2008). The external public characteristics, such as the number of members of the public in question, the credibility of the source, past successes and failures of groups to evoke change, the amount of advocacy the organization practices and the involvement of its members. The issue under consideration, for example, the size, the stake, and the complexity of the issue that has caused the crisis.

The internal variable factors identified in the contingency theory of accommodation, are clustered in the following groups: Characteristics of the organization, for example, if it is centralized geographically or not, how old the organization is, the value that is placed on tradition, the degree of economic stability in the organization, the corporate culture, and other issues the organization have currently or have had in the past. Characteristics of the public relations department, the individual public relations practitioners and top management, such as the qualifications of the public relations staff, the experience levels of dealing with conflict, the general communication competency in the public relations department, the potential to practice various public relations scenarios, the location of the public relations department in the organizational hierarchy, the funding and time available to deal with external publics, and management's support of the public relations department. Internal threats, such as the economic considerations in the organization, marring of employees and stockholders' perception of the organization, and the marring of the personal reputation of the company decision makers. Characteristics of organization-public relationships, for example, the trust between an organization and its external publics, the dependency of the parties involved, and any ideological barriers that may exist between the organization and its publics. In their 1999 follow-up paper, Cancel et al. perform extensive interviews with industry professionals, which are used to 
determine if the 87 identified factors hold true. A few are dropped, and others added, but generally, there seems to be agreement on the validity of the variables, and the participating practitioners recognized that the identified internal and external characteristics were at play in strategic conflict management.

The case study in Pang et al. (2006) shows that the internal variables greatly impacted how a Fortune 500 company struggled to adopt a regional crisis communication master plan. Studying the dominant coalition and corporate communication practitioners as separate publics in the contingency continuum, Peng et al. found that the dominant coalition reluctantly accommodated regional practitioners' plan as a "basic" preventative measure against negative media coverage and threats to the company's reputation, but advocated their stance that the adoption of the plan was not seen as a high priority due to low enlightenment, corporate culture, and other internal factors. Conversely, line managers were more eager to accommodate, even as the plan was perceived as an auxiliary function to the company. Peng et al. show the expansion of theoretical coverage of the contingency theory to the intra-organizational level, and find that on a practical level, conflict management and public relations efforts cannot be functional without organizational support and adoption. That is, a wide-reaching organizational communications plans cannot be coordinated in large companies without the commitment and advocacy of the dominant coalition. While advocacy of line management seemed helpful in this case, this practice cannot benefit the organization as a whole. Cancel et al. (1999) supports the notion that negative predisposing factors must be eliminated before intra-organizational advocacy can take place: "predisposing variables influence location along the continuum before the corporation enters into a particular situation involving an external public" (p. 190).

Heath (1997) stresses that an organization's persona or personae can be key to how the organization is perceived in a crisis situation and that personae are formed through public policy 
stances, defined by differentiation, association, identity, and goodwill. Public policy stances or issues communication coupled with positive personae as an outcome can be pitched to the dominant coalition as initial communication tactics in moving towards implementing a full communication plan for the organization as these seem to serve as crisis prevention measures.

Cameron et al. (2008) explicate conflict management as a life cycle with four discrete phases, including proactive, strategic, reactive, and recovery phases. Proactive and strategic phases are more concerned with conflict prevention and concern. Reactive and recovery phases involve response to a crisis or conflict and rebuilding approaches. This study is most concerned with the reactive phase, which is explained as): "Once the issue or imminent conflict reaches a critical level of impact on the organization, the public relations professional must react to events as they unfold in the external communication environment" (Cameron, Wilcox, Reber, \& Shin, 2008, p. 44).

There are multiple advantages of using the contingency theory. First and foremost, it is complex as it can take into account almost 100 factors in the crisis situation. Furthermore, it considers the dynamic nature of crises, as it allows the ideal stance on the continuum to move, as new information is presented. However, it only relates to crisis communication on one dimension: accommodate or advocate, and it does not directly take into account how this can be done in the best possible way. It also does not specifically pertain to social media, but the many factors cover so many dimensions, so the approach is still more than useful during social media crisis situations. 


\section{Situational Crisis Communication Theory}

The perhaps most referenced crisis communication theory these years is the situational crisis communication theory posited by Coombs (2007). Unlike many other crisis communication theories, there is a normative aspect to the situational crisis communication theory. When reacting to a crisis, the very first job of the public relations manager should be to inform the stakeholders, so no harm is done (Coombs, 2007). Afterward, the PR practitioner should then asses the degree of reputational threat, and then what type of crisis is taking place.

The situational crisis communication theory has its theoretical roots in Attribution Theory (Heider, 1958). The fundamental argument is that people look to attribute causality and responsibility when something goes wrong, for example during and after a crisis. However, Heider's Attribution Theory does not go into details directly pertinent to crises or crisis communication.

A key component from situational crisis communication theory is the grouping of crises into three different clusters: victim, accidental and intentional. For each cluster there are several response tactics depending on outside factors. The victim cluster is a crisis where the organization also is a victim. This could for example be a natural disaster, such as a hurricane or earthquake that can damage an organization, a false rumor with damaging information that is being circulated about the organization, workplace violence where current or former employees attack the organization or its employees, and product tampering or other forms of malevolence where external agents cause damage to an organization. This was seen in the Tylenol crisis of 1982 where a person tampered with the product, which leads to a series of poisoning deaths in the Chicago metropolitan area. In general, crises in the victim cluster has a minimal attribution of crisis responsibility and come with a mild reputational threat. (Coombs, 2007). 
In the accidental cluster, the organizational actions that led to the crisis were unintentional. Crises in the accidental cluster can also be challenges, such as stakeholders claiming an organization is operating in an inappropriate manner, but where it isn't immediately obvious if this is the case. The crises in this cluster can also be technical-error accidents where a technology or equipment failure cause an industrial accident or technical error-product harm where a technology or equipment failure causes a product to be recalled. The accidental cluster crisis also has a minimal attribution of crisis responsibility but cause a moderate threat to the organization's reputation (Coombs, 2007).

The intentional cluster contains the types of crisis that provide the biggest threats to an organization. They can be human errors from excessive negligence that causes industrial accidents or product harm, organizational misdeeds where stakeholder is deceived resulting in no or some injuries, organizational misdeed management misconduct where laws or regulations are knowingly violated by the management and organizational misdeeds with injuries where stakeholders are placed at risk by the management's actions, and injuries subsequently occur. The internal cluster crisis has the strongest attributions of crisis responsibility and possesses the most severe reputational threat (Coombs, 2007).

Furthermore, Coombs also defines three groups of response strategies that are somewhat similar to those identified by Benoit in his image restoration theory: Denial, collaboration, and restoration. Among each of those categories are several response tactics. The tactic that is most appropriate in a given situation depends on the type of crisis cluster and the severity of the crisis, Coombs explains.

Methodologically, the situational crisis communication theory is very well tested through a series of experimental studies. Using experiments is necessary in crisis communication 
research if one is to have a high degree of internal validity. Case studies and surveys can provide many relevant insights, but there is an invariable risk of confounding factors. By using experiments instead, researchers can isolate the factor of interest, and thus ensure a higher degree of internal validity. The downside of using experiments, is that the external validity can be limited.

\section{Conversational Human Voice}

An approach to expanding the explanatory powers of the broader crisis communication theories is to look at more specific strategic communication tactics. One of these is to communicate with a so-called conversational human voice. The idea first developed from the social presence theory proposed by Short et al. (1976). A key notion of social presence theory is that in any communication, the degree to which the other party is perceived as being real is vital for effective communication. In a time where an ever-increasing proportion of communication is taking place online, the necessity of perceiving the other party as real becomes even stronger. Therefore, publics do not want messages from organizations that are delivered in a corporate tone. Instead, they expect a genuine dialogue that takes place in a conversational voice (Kelleher, 2009).

Scholarship has established that communicated commitment and conversational human voice correlate positively with public relations relationship outcomes (Kelleher, 2008; Kelleher \& Miller, 2006; Lim, Nicholson, Yang, \& Kim, 2015; Park \& Cameron, 2014). One possible explanation could be that when strategic communicators are using a conversational human voice, audiences don't see them as equals more than professionals trying to sell a product or a message. 
'The best of the people in PR are not PR Types at all . . . they're the company's best conversationalists', (2001, p. 90) Searls and Weinberger (2001) explained.

Kelleher and Miller (2006) identified the concept of conversational human voice as a key predictor of relational outcomes to explore how conversational human voice works theoretically and empirically. Other studies show that source tone has been integral to developing relations online (Park, 2011). More specifically, social networking sites are catered to facilitating dialogue between organizations and publics (Rybalko \& Seltzer, 2010). For instance, human voice in organizational social media contributes to better relationships between organizations and their respective publics (Kelleher \& Miller, 2006).

Interactivity is another key component to the success of human voice via social media since social media facilitated dialogic communication. In an experimental setting, interactivity contributed to higher perceived reputation (Jo \& Kim, 2003). Thus, using human voice and applying multimedia and social media can lead to improved organization-public relationships (Sweetser \& Metzger, 2010).

So, the evidence points clearly towards communicating with a conversational human voice and interactive communication both can be effective in crisis communication under the right circumstances. Both of these concepts have been described as key components of a broader concept, authenticity, that appears to hold exciting prospects for strategic communicators, including crisis communication scholars and practitioners. However, so far, the amount of scholarly research that has been done exploring the impact that authenticity can have on crisis communication is very limited. 


\section{Authenticity}

In recent years, the concept of authenticity has received a growing amount of attention from both public relations practitioners and scholars in a wide range of fields. Edwards even argues that the whole communications industry is "built on a notion of authenticity" (Edwards, 2010, p. 192).

One reason for the increasing attention being paid to authenticity is the development of social media that quickly has become an important part of most people's daily lives. And a strong presence on social media is now vital for organizations that want to enhance a perceived notion of corporate transparency and authenticity to build solid relationships (Men \& Tsai, 2014, 2016), and it has become critical for the public to experience that an organization appears authentic, open, or transparent when they communicate (Molleda, 2010).

As a natural development, authenticity has become a central topic of debate for public relations practitioners focusing on social media (Edwards, 2010; Gilpin, Palazzolo, \& Brody, 2010; Sisson \& Bowen, 2017). As the use of social media has become more prevalent as a communication channel between private citizens and organizations, publics have increasingly demanded greater transparency (McDonald, 2016). With this, authenticity becomes essential, Molleda (2009) argues, and it now lies near the heart of the strategic communication industry (Molleda \& Jain, 2013). Molleda (2009) explains that as changing technology allows many new voices to reach a wide audience without any editorial process, it can be hard to gauge what is factual and what is not, so communication that is experienced as authentic suddenly becomes a premium.

Authenticity is far from a new concept. Its roots can be traced all the way back to Greek philosophy, and it has been studied in a wide variety of disciplines such as art, anthropology, 
psychology, sociology, education, marketing, branding, and strategic communication. (Shen \& Kim, 2012). Philosophers have equated authenticity to "notions of correspondence and genesis" (Molleda, 2009, p. 88). These notions involve Socrates' 'self-understanding,' Kierkegaard's “'essential knowledge and subjective truth, (Kernis \& Goldman, 2006), as well as Heidegger’s (1949) idea of separating one's own existence from others, and Trilling's (1973) view of constructing one's way of being — the "credibility of existence"' (p. 93, Kernis \& Goldman),"

Communication scholars also seem in agreement that authentic communication is a contributing factor for successful organization-public relationships (Mazzei et al., 2016; Shen \& Kim, 2012), and this notion also appear to be supported in studies examining public relations practitioners (McDonald, 2016; Men \& Tsai, 2016; Sisson \& Bowen, 2017).

Despite this recognition from both public relations scholars and practitioners that authenticity is a key concept and an important trend, it is relatively limited how much scholarly research has been done on the concept in a public relations and relationship management research (Shen \& Kim, 2012) and particularly in a crisis communication context (Grunig and Kim, 2011).

\section{Defining Authenticity}

Although a great amount of scholarly attention has been paid to authenticity in multiple fields of research, a deeper dive into the literature reveals that there is not much agreement on how authenticity should be defined. Lehman et al. point out: "scholars use the same lexical term but often approach the concept from different perspectives and apply different meanings" (Lehman et al., 2019, p. 2). In fact, few authors actually define the term, and there is no general definition that is broadly accepted (Beverland, 2005; Margaretten \& Gaber, 2012). 
One hindrance to a universally accepted definition of authenticity is that the construct can be present in a variety of forms. "Authenticity can be inherent in an object, come from a relation between an object and/or a historical period, an organization form, or nature, or be given to an object by marketers and consumers." (Beverland, 2005, p. 1006). Peterson adds that "authenticity is not a property of entities but, instead, "a claim that is made by or for [them] ... and either accepted or rejected by relevant others" (Peterson, 2005, p. 1086), and Knudsen and Waade (2010) suggested that authenticity is "neither a 'thing' you can possess nor a 'state of mind' but something people can do and a feeling which is experienced' (p. 1, italics in original). Shen and Kim (2012) also point out that authenticity is not an either/or condition, but a matter of degree. "That is, one is not either authentic or inauthentic; rather, one can be positioned along the continuum of authenticity to inauthenticity." (p. 373).

Although a great amount of scholarly attention has been paid to authenticity in multiple fields of research, there is not a consensus of how the concept should be defined, but there are some general descriptions and traits that are repeated. The Oxford English Dictionary (2017) define being authentic is being "in accordance with fact or stating the truth, and thus worthy of acceptance or belief; of established credit; able to be relied on; truthful, accurate." It also states that in recent use, being authentic is chiefly overlapping with having the quality of verisimilitude and being true to life. Authenticity is "the fact or quality of being true or in accordance with fact, veracity, and correctness. It is also stated as being "the quality of truthful correspondence between inner feelings and their outward expression, unaffectedness and sincerity" and "(t)he quality or fact of accurately reflecting a model or exemplar, or of being traditionally produced or presented." Most of the published literature on authenticity use definitions that have a significant overlap with these, and there appear to be a general consensus that authenticity is 
referring to something real, genuine or true, or in other words, that an individual, collective or object "are what they appear to be or are claimed to be". (Trilling, 1972, p. 92).

This study uses the following definition of authenticity: "Authentic behavior is true, transparent, and consistent." The definition is inspired by Shen and Kim (2012) who looked at earlier research on the construct in psychology, business management, and strategic communication and identified three key components of perceived authentic organizational behavior: truthfulness, transparency, and consistency.

Truthfulness. In Shen and Kim's definition of authenticity, truthfulness reflects not only honesty but also knowing and acting unbiasedly in accordance with one's values. "Authentic individuals should learn about themselves, unbiasedly process and evaluate self-relevant information, act in accordance with their true beliefs, values, and desires, and strive for genuineness in their close relationships. "(p. 374). In the context of organizational communication, this means that an organization not only should be honest in their communication, but also stay true to themselves, and not be affected by outside forces. The notion of something or someone being genuine, real, or true is persistent in most definitions of authenticity (Dutton, 2003; Kennick, 1985; Shen \& Kim, 2012). Frosh defined authenticity from a mass cultural production approach as: [...] "truthto-oneself," a project of ontological fidelity that takes particular discursive forms: in the aesthetic realm, it stresses the creativity of the individual artistic personality ... and the formal and expressive uniqueness of the artwork. (2001, p. 542), and in a similar vein, Zickmund wrote that authenticity "is a process of being true to one's own self, of living life according to one's own being" (2007, p. 407). Correspondingly, authenticity has also been defined with a focus on sincerity, innocence, and originality (Fine, 2003), and related to concepts such as being real 
natural, honest, simple and unspun (Boyle, 2004; Lehman et al., 2019; Napoli, Dickinson, Beverland, \& Farrelly, 2014). Other have stressed concepts of "faithfulness" and "truth" (Morhart, Malär, Guèvremont, Girardin, \& Grohmann, 2015), sincerity (Beverland, 2005) and trust (Füller, Schroll, \& von Hippel, 2013).

Transparency. According to Shen and Kim, transparency indicates an organization's behavior of admitting, accepting, and learning from their own mistakes objectively, and it is facilitated by symmetrical communication strategy in an organization. Transparent communication is at the core of authenticity (Fombrun, Van Riel, \& Van Riel, 2004), and it involves engaging stakeholders in an ongoing conversation about an organization's decisions, actions, and behavior. To appear authentic, Molleda and Jain (2013) argues, an organization should periodically and accurately share information with its stakeholders, engage with them in a dialogue and disclose its values, motives, and beliefs in a manner that enables stakeholders to more accurately assess the identity and integrity its actions. In an organizational leadership context, Walumbwa et al (2010) defined authenticity as the degree to which a leader is aware of and displays patterns of openness in their behavior to others through sharing the sharing "the information needed to make decisions, accepting others' inputs, and disclosing his/her personal values, motives, and sentiments in a manner that enables followers to more accurately assess the competence and morality of the leader's actions" (p. 901, reference in Molleda and Jain, 2013).

Similarly, Kernis and Goldman (2006) approached the topic of perceived authenticity from a social psychology point of view and found that open communication can lead to authentic individual behavior, and extending it to an organizational context, they hypothesize that an organization becomes authentic when it openly and symmetrically communicates with its publics about its decisions and actions. They furthermore contended that authenticity consists of four distinct, but interrelated components: awareness, unbiased processing, behavior, and relational 
orientation. In short, this means that individuals that want to be perceived as authentic should learn about themselves, unbiasedly process and evaluate self-relevant information, act in accordance with their true beliefs, values and desires, and finally, they should strive for genuineness in their close relationships.

There is also anecdotal evidence of people equating openness with authenticity. In a study of school climates and the perceived authenticity of principals and teachers, Hoffman (1993) found that the more open a school climate was, which includes open communication, then more authentic the principal and teacher is seen as by the parents. Similarly, being engaging leads to a greater degree of perceived authenticity. Men and Tsai (2014) developed a model that measures public engagement with corporate pages on social networking sites and evaluates the influence of such engagement on important perceptual, relational, and behavioral outcomes. Their study found, amongst other findings, a positive correlation between public engagement and perceived corporate authenticity.

Consistency. According to Kim and Shen (2012), consistency indicates that the value, belief, and rhetoric of an organization should be in accordance with its behaviors and be consistent over time. Formbrum and van Riel argued that in an age of complexity, it is vital for organizations to demonstrate consistency between what they say, what they are, and most importantly, what actions and decisions they make, to be seen as authentic (2004). Molleda (2010) found that perceptions of authenticity are shaped by stakeholders evaluating organizational claims against its actions and behaviors. If there are discrepancies between what is being said and done, the organizations will be perceived as considerably less authentic. In a study focusing on authenticity in branding, Spiggle, Nguyen, and Caravella (2012) demonstrate that consistency is a key for brands that want to be perceived as authentic. Stakeholders consistently evaluate organizational claims against its actions and behavior to and base their evaluations of consistency. 
The Axioms of Authenticity

However, as previously discussed, being sincere, honest and accurate does not fully encapsulate authenticity, according to some parts of the literature. In their book, Gilmore and Pine (2007) identified five types of authenticity; natural, original, exceptional, referential and influential. Based on those, they also presented five axioms for authenticity: If you are authentic, then you don't have to say you're authentic. If you say you're authentic, then you'd better be authentic. It's easier to be authentic if you don't say you're authentic. It's easier to render offerings authentic if you acknowledge they're authentic. You don't have to say your offerings are inauthentic if you render them authentic. (p. 90, italics in original). These axioms touch on some of the main ideas that also are present in other scholarly work on authenticity.

\section{The Anti-commercial Aspect of Authenticity}

In a study of what makes luxury wine brands appear authentic, Beverland defined authenticity as a "story that balances industrial (production, distribution and marketing) and rhetorical attributes to project sincerity through the avowal of commitments to traditions (including production methods, product styling, firm values, and/or location), passion for craft and production excellence, and the public disavowal of the role of modern industrial attributes and commercial motivations" (Beverland, 2005, p. 1008). Here, an accurate and sincere portrayal of the brand and its roots is not enough to be considered authentic. It also has to secure a public disavowal of the role of modern industrial attributes and commercial motivations. This anti-commercial or anti-profit-seeking perspective is a general theme among some descriptions of authenticity. Similarly, Fine (2003) found that for artists, their perceived authenticity 
diminished when they openly adopted the trappings of the market such as 0800 numbers and deliberate customer targeting (Napoli et al., 2014).

Thompson et al. (2006) found that for some businesses, for example, a niche coffee brand, contrasting themselves to a large commercial brand, such as Starbucks leads to an increase in the perceived authenticity from the audience. (Thompson, Rindfleisch, \& Arsel, 2006) In fact, such brands that are being perceived as being "above commerce" would often benefit from downplaying their marketing strategy and commercial skill from an outward projection of images related to craft production, heritage and tradition (Beverland, 2005; Lehman et al., 2019).

Holt even goes one step further and argues that postmodern consumer culture has adopted a particular notion of authenticity that has proved especially challenging to marketers: "To be authentic, brands must be disinterested; they must be perceived as invented and disseminated by parties without an instrumental economic agenda, by people who are intrinsically motivated by their inherent value. Postmodern consumers perceive modern branding efforts to be inauthentic because they ooze with the commercial intent of their sponsors. (Holt, 2002, p. 83). This presents quite a paradox for the brands in question. To be perceived as authentic, they have to present a picture that often is not fully real, accurate or sincere - that the economic agenda is not their primary agenda.

Another paradox that might be frustrating for communicators whose goal is to be as authentic as possible is that real authentic speech should be "displaying the features of spontaneous, unrehearsed discourse" (Montgomery, 2001, p. 447), which conflicts with the desire to be prepared and rehearsed. And authentic communication is successfully done, then that information should not be shared broadly. Kovács, Carroll and Lehman found that for 
organizations, touting one's own authenticity can backfire, making one come off as anything but authentic (2017).

One way to successfully pursue communication that is perceived as more authentic is by incorporating narratives. In Beverland's 2005 study of luxury wine producers, he found that the development of a sincere story consisting of demonstrable referents to place, tradition, and noncommercial values were crucial to conveying brand authenticity. And in an experiment, Chiu, Hsieh, and Kuo (2012) confirmed that aligning brand stories with products led to significantly higher degrees of perceived authenticity.

\section{Benefits of Authenticity}

Generally, there seem to be an acceptance that there are positive associations with authenticity, and apparently, this is for a good reason, as there are multiple benefits of being perceived as authentic. A handful of studies in strategic communication, psychology, and business management have shown that perceived notions of authenticity are positively correlated with perceived organization-public relationship quality. When brands manage to successfully present themselves as authentic, it leads to desirable outcomes such as greater brand identification and attachment among the target costumers (Baker, Rapp, Meyer, \& Mullins, 2014; Morhart et al., 2015), and it also has a significant impact on brand trust (Eggers, O’Dwyer, Kraus, Vallaster, \& Güldenberg, 2013). Kent and Taylor (2002) briefly discussed genuineness as a subprinciple of a dialogic public relations theory. They reasoned, "Organizations and publics that deal truthfully with one another are much more able to come to mutually beneficial solutions"' (p. 29). That is, organizations engaged in authentic behavior will be more likely to have quality relationships with their publics. 
On a similar notion, Kernis (2003) tied perceived authenticity together with the relationships an individual can develop with others. He argues that individuals that are being perceived as authentic also are seen as exhibiting higher levels of self-esteem, and they are more likely to develop good relationships with other individuals. Likewise, Walumbwa et al. (2005) found that authentic leadership is positively associated with individual followers' job satisfaction and job performance. And if there still is any doubt whether authenticity can have positive impacts, then Kernis and Goldman (2006) delivered one of the most convincing arguments, when their data revealed that perceived authenticity increases relational satisfaction in romantic relationships.

Mazzei et al. (2016) tested the impact of perceived authenticity in relation to so-called megaphoning behavior, which refers to employees voluntarily forwarding information about an organization's strengths or weaknesses. They found that organizations' authentic behavior is positively related to their positive megaphoning behavior, but it is mediated by organizationemployee relationship. Furthermore, they found that perceived authenticity of organizational behavior was more effective than employees' intrinsic motivation when it came to predicting positive megaphoning behavior during crisis situation.

Having a reputation as an authentic organization can make a significant difference when extraneous factors impact one's organization. Fombrun and van Riel (2003) argue that when financial markets crash, firms that have a reputation for being authentic are likely to experience less financial volatility compared their competitors. Shen and Kim (2012) found that perceived authenticity was positively correlated with indicators for organizational behavior, organizationpublic relationship quality and what they called positive megaphoning, which refers to the likelihood of employees' voluntarily sharing information organizational strengths or weaknesses. Similar conclusions were reached by other communication scholars. Furthermore, Men and Tsai 
(2016) established positive associations between organizational authenticity and reputation, organizational communication effectiveness, and quality organization-public relationships. 


\section{CHAPTER 3}

\section{HYPOTHESES AND RESEARCH QUESTIONS}

To briefly summarize chapter 2 , there is ample evidence of authenticity having a positive influence when used in strategic communication settings. With an information flow going faster and faster, and a myriad of competing messages from organizations and businesses, audiences have shown a preference for authentic messages - that is messages that are truthful, transparent, and consistent. Organizations that engage in authentic behavior are more likely to have quality relationships with their publics (Men \& Tsai, 2016; Shen \& Kim, 2012), and there is reason to believe that this would also be the case in a crisis communications setting. Trust in an organization, a concept related to authenticity, has been found to be a key indicator in determining crisis communication outcomes (Kim, Kiousis, \& Molleda, 2015), and case studies have provided anecdotal evidence of authenticity having a positive impact on crises outcomes (Mazzei et al., 2016; Sisson \& Bowen, 2017), so it can be hypothesized that authenticity has a positive impact on crisis communication outcomes. The impact from an organizational reputational crisis can play out in multiple ways, so in this study, four different crisis outcomes are evaluated.

One of the most-often cited measures of crisis response success is crisis responsibility attribution. A key objective for crisis managers should be to avoid or minimize the reputational damage ton an organization (Pearson \& Mitroff, 1993). During and after a crisis, people or publics seek causes and evaluate organizational responsibility for the crisis. "The more publics attribute crisis responsibility to an organization, the stronger the likelihood is of publics developing and acting upon negative images of the organization" (Coombs \& Holladay, 1996, p. 
282). This can be problematic for the organization because attributions of responsibility can lead to stronger feelings of anger and a more negative view on an actor's image (Weiner, Amirhan, Folkes and Verette, 1987). Since it is posited that authentic crisis communication leads to more positive crisis outcomes, is it hypothesized that:

H1: A crisis response that is authentic will lead to a lesser degree of crisis responsibility attribution than a crisis response that is not authentic will do.

Another relevant crisis parameter is whether the organization's reputation is damaged by the crisis. Managing the organizational reputation during a crisis is the central focus of the situational crisis communication theory, (Coombs \& Holladay, 2002) since an organization's reputation can have substantial economic significance (Coombs, 2007). Dukerich and Carter (2000) argue that organizational reputations primarily are based on perceptions more than a situation's actualities, so it is a parameter that really reflects the successful communicative effort, regardless of the crisis.

H2: A crisis response that is authentic will lead to a better organizational reputation than a crisis response that is not authentic will do.

If a reputational crisis is mishandled, it can lead more than just attributed crisis responsibility and lesser thoughts of the organizational reputation, it can also spark anger among the publics. Anger is the affective feeling that most often is associated with crises (McDonald and Hartel, 2000), and it has been found to translate into purchase intentions (Jorgenson, 1996), 
so it can have a direct negative impact on an organization's economy. Earlier studies have found that crisis attribution is a predictor of anger (Coombs and Hollday, 2005).

H3: A crisis response that is authentic will lead to less anger than a crisis response that is not authentic will do.

Another parameter for crisis communication is the degree to which publics would be willing to speak positively about the organization following a crisis. Word-of-mouth has been found to have a strong impact on consumers' attitude (Brown and Reingen, 1987), and in an earlier study, Mazzei et al. (2016) found that authentic crisis communication had a positive impact on an organization's employees willingness to positively share word-of-mouth about the organization.

H4: A crisis response that is authentic will lead to a greater intention of positively spreading word of mouth about an organization.

The contingency theory of accommodation posits that crisis managers should find the right balance between advocating and accommodating, based on a series of internal and external variables. In both scenarios involving the American Red Cross and United Airlines that are tested, there are factors pointing in each direction. The characteristics, such as the size, history and market positions of the organizations would indicate that accommodation might be the best option, while the potential legal threats instead would be an argument for advocacy, or at least only limited accommodating. But for both scenarios, the pivotal factor is the issue under consideration. Based on the descriptions in the crisis scenarios, both organizations appear to have 
caused the crisis themselves, and there is, therefore, a reason to believe that an accommodative crisis response would lead to the best crisis outcomes. Furthermore, Ott and Theunissen (2015) argued that strategies of advocacy, denial or diminishing criticism were not effective crisis strategies on social media, but noted accommodative strategies were.

H5: A crisis response that is accommodative will lead to a lesser degree of crisis responsibility attribution than a crisis response that is not authentic will do.

H6: A crisis response that is accommodative will lead to a better organizational reputation than a crisis response that is not authentic will do.

H7: A crisis response that is accommodative will lead to less anger than a crisis response that is not authentic will do.

H8: A crisis response that is accommodative will lead to a greater intention of positively spreading word of mouth about an organization.

It is unclear if authentic crisis responses are more or less effective when given as part of an accommodative response, comparing to one that is advocating. If the evidence of an organization's misdeeds in a crisis is convincing to the public, then it could be contended that the organization must accommodate for a crisis response to appear authentic to the public. If no action is taken to make a wrongdoing right, then authentic response will appear as empty words, that are insincere and therefore unlikely to have an effect. Additionally, for a crisis response to be perceived as authentic, there would need to be an aspect of transparency, and in many cases, being transparent would be seen as being part of an accommodative effort. 
On the other hand, it can be argued that when organizations refuse to accommodate in response to a crisis, they appear consistent and staunch, as they are unwilling to cave to outside pressures. This is consistent with some definitions of being true to one's self. If the outside pressure is harsh, it might even make an organization appear even more authentic, as it can be perceived as staying true to its values by withstanding the storm and sticking to its values, even if it potentially can come at a high price - something that is very strongly associated with authentic behavior. The advocating stance would therefore in effect highlight the authentic aspect and thus strengthen its impact. However, for this to work it would be vital for the organization to convince its key stakeholders that it isn't at fault for the crisis, as it otherwise could backfire and appear insincere. So, it would be particularly hard to do for an organization reaction to crisis from the intentional crisis cluster.

R1: Is there an interaction effect between presence of authenticity and type of crisis response on crisis responsibility attribution?

R2: Is there an interaction effect between presence of authenticity and type of crisis response on organizational reputation?

R3: Is there an interaction effect between presence of authenticity and type of crisis response on anger following a crisis?

R4: Is there an interaction effect between presence of authenticity and type of crisis response on the intention of positively spreading word of mouth about an organization following a crisis? 
Table 3. 1. Summary of Theory, Hypotheses, and Research Purposes

\begin{tabular}{|c|c|c|c|}
\hline Purpose & Hypotheses/ RQ & Theory & Measures \\
\hline $\begin{array}{l}\text { To test the } \\
\text { effects of } \\
\text { communicating } \\
\text { with } \\
\text { authenticity on } \\
\text { crisis } \\
\text { communication } \\
\text { outcomes }\end{array}$ & $\begin{array}{l}H 1: \text { A crisis response that is authentic will } \\
\text { lead to a lesser degree of crisis responsibility } \\
\text { attribution than a crisis response that is not } \\
\text { authentic will do. } \\
H 2: \text { A crisis response that is authentic will } \\
\text { lead to a better organizational reputation } \\
\text { than a crisis response that is not authentic } \\
\text { will do. } \\
\text { H3: A crisis response that is authentic will } \\
\text { lead to less anger than a crisis response that } \\
\text { is not authentic will do. } \\
\text { H4: A crisis response that is authentic will } \\
\text { lead to a greater intention of positively } \\
\text { spreading word of mouth about an } \\
\text { organization. }\end{array}$ & $\begin{array}{l}\text { Authenticity in } \\
\text { strategic } \\
\text { communication } \\
\text { (Men \& Tsai, } \\
\text { 2016; Molleda \& } \\
\text { Jain, 2013; Sisson } \\
\text { \& Bowen, 2017). } \\
\text { SCCT (Coombs, } \\
\text { 2007). } \\
\text { Contingency } \\
\text { theory of } \\
\text { accommodation } \\
\text { (Cancel et al., } \\
\text { 1997, 1999) }\end{array}$ & $\begin{array}{l}\text { IVs: Presence } \\
\text { of authenticity } \\
\text { in crisis } \\
\text { communication } \\
\text { DVs: Crisis } \\
\text { Responsibility } \\
\text { Attribution, } \\
\text { Organizational } \\
\text { Reputation, } \\
\text { Anger, WOM- } \\
\text { intention. }\end{array}$ \\
\hline $\begin{array}{l}\text { To test the } \\
\text { effects of being } \\
\text { accommodating } \\
\text { on crisis } \\
\text { communication } \\
\text { outcomes }\end{array}$ & $\begin{array}{l}\text { H5: A crisis response that is accommodative } \\
\text { will lead to a lesser degree of crisis } \\
\text { responsibility attribution than a crisis } \\
\text { response that is not authentic will do. } \\
\text { H6: A crisis response that is accommodative } \\
\text { will lead to a better organizational reputation } \\
\text { than a crisis response that is not authentic } \\
\text { will do. } \\
\text { H7: A crisis response that is accommodative } \\
\text { will lead to less anger than a crisis response } \\
\text { that is not authentic will do. } \\
\text { H8: A crisis response that is accommodative } \\
\text { will lead to a greater intention of positively } \\
\text { spreading word of mouth about an } \\
\text { organization. }\end{array}$ & $\begin{array}{l}\text { Contingency } \\
\text { theory of } \\
\text { accommodation } \\
\text { (Cancel et al., } \\
\text { 1997, 1999) } \\
\text { Crisis } \\
\text { responsibility } \\
\text { attribution } \\
\text { (Coombs and } \\
\text { Holladay, 1996; } \\
\text { Weiner et al., } \\
\text { 1987). }\end{array}$ & $\begin{array}{l}\text { IV: Degree of } \\
\text { accommodation } \\
\text { in crisis } \\
\text { communication } \\
\text { DVs: Crisis } \\
\text { Responsibility } \\
\text { Attribution, } \\
\text { Organizational } \\
\text { Reputation, } \\
\text { Anger, WOM- } \\
\text { intention. }\end{array}$ \\
\hline $\begin{array}{l}\text { To test the } \\
\text { interaction } \\
\text { effects of } \\
\text { authenticity } \\
\text { and } \\
\text { accommodation } \\
\text { on crisis } \\
\text { communication } \\
\text { outcomes }\end{array}$ & $\begin{array}{l}R 1: \text { Is there an interaction effect between } \\
\text { presence of authenticity and type of crisis } \\
\text { response on crisis responsibility attribution? } \\
R 2 \text { : Is there an interaction effect between } \\
\text { presence of authenticity and type of crisis } \\
\text { response on organizational reputation? } \\
R 3: \text { Is there an interaction effect between } \\
\text { presence of authenticity and type of crisis } \\
\text { response on anger following a crisis? } \\
R 4: \text { Is there an interaction effect between } \\
\text { presence of authenticity and type of crisis } \\
\text { response on the intention of positively } \\
\text { spreading word of mouth about an } \\
\text { organization following a crisis? }\end{array}$ & $\begin{array}{l}\text { Authenticity in } \\
\text { strategic } \\
\text { communication } \\
\text { (Men \& Tsai, } \\
\text { 2016; Molleda \& } \\
\text { Jain, 2013; Sisson } \\
\text { \& Bowen, 2017). } \\
\text { SCCT (Coombs, } \\
\text { 2007). } \\
\text { Contingency } \\
\text { theory of } \\
\text { accommodation } \\
\text { (Cancel et al., } \\
\text { 1997, 1999). }\end{array}$ & $\begin{array}{l}\text { IV: Degree of } \\
\text { accommodation } \\
\text { in crisis } \\
\text { communication } \\
\text { DV: Crisis } \\
\text { Responsibility } \\
\text { Attribution }\end{array}$ \\
\hline
\end{tabular}




\section{CHAPTER 4}

\section{METHODOLOGY}

Overview

To test the hypotheses and answer research questions, a 2 (tone: authentic vs. not authentic) x 2 (type of response accommodative vs. advocating) between-subjects experimental design was applied and conducted through two separate surveys. The first survey to test the manipulation of the instruments and the second to test the hypotheses and answer the research questions. Both surveys were experiments, where the participants saw multiple crisis scenarios and were then assigned to read different types of crisis responses before answering questions.

Four different crisis scenarios with modified responses were created for the experiment, but after a test of the manipulation check, two of the crisis scenarios were dropped. The two remaining crisis scenarios were one involving a not-for-profit organization, the American Red Cross, and one involving a for-profit organization, United Airlines. The American Red Cross crisis is centered around accusations of misappropriation of funds and mismanagement of projects in Haiti. The United Airlines crisis was centered around a viral video of airport security dragging a screaming passenger off an overbooked flight after he already had taken his place on board. A cross combination of the two manipulated factors, authentic/not authentic and accommodative/advocating, created four different responses for each of the crisis scenarios. As crisis communication outcomes, the following dependent variables were measured: crisis responsibility, organizational reputation, anger, and word-of-mouth intention. 
For the manipulation test, a total of 170 undergraduate students were recruited from a journalism course at the University of Missouri. Responses from 45 participants were excluded from data analysis through data screening and cleaning procedures leaving a total sample size of 125. For the primary test, participants were recruited through Qualtrics Panels. After data screening and cleaning procedures, a total sample size of 229 was left.

\section{Study Design}

For both experiments, the participants all saw the same crisis scenarios in randomized order, and for each scenario they saw they were randomly assigned one of the four different types of crisis responses (authentic and accommodative, authentic and non-accommodative, nonauthentic and accommodative or non-authentic and non-accommodative.) After seeing each crisis scenario and reading the crisis responses, the participants were asked to answer questions measuring the dependent variables. Hypotheses and research questions were tested using independent samples t-tests and repeated measures analysis of variance (ANOVA) procedures conducted through STATA 15.1 statistical software.

\section{Participants}

For the manipulation check, participants were recruited from a large-lecture introductory journalism course at the University of Missouri. The participants received extra credit as an incentive for their participation and were also offered the choice of doing an extra assignment for the extra credit instead. Using undergraduate students as study participants can, in some circumstances, pose a threat to both the external and internal validity of the study, since they are 
not necessarily representative of the broader population. But this is justified since there is no apparent reason to believe that college students would have a different experience of authenticity and accommodation than the rest of the population and because this manipulation test only serves to measure if the stimuli are manipulated as intended, not to actually test the hypotheses. Additionally, Shapiro (2002) maintained that controlled experiments with non-probability samples are both a legitimate and efficient method of examining theoretical relationships and processes since they provide important information about whether an expected relationship holds or fails for a target group of people.

A total of 170 students participated in the manipulation test. 23 did not finish the survey, and 22 were dropped due to data screening and cleaning procedures, leaving 125 participants. Additionally, respondents' answers were changed to missing for a given scenario if they spent less than 30 seconds on a page since this indicates they haven't read the stimuli before beginning to answer (each of the crisis scenarios and answers took approximately two minutes to read). Furthermore, if participants spent less than ten seconds from their first click on a survey to their last, their answers also were changed to missing for that scenario. The reasoning for this was that with 15 questions in randomized order for each scenario, spending less than 10 seconds would indicate that they had not read the questions.

The participants in the manipulation check were overwhelmingly female $(76.80 \%, \mathrm{n}=96)$ and only $23.20 \%(\mathrm{n}=29)$. They ranged in age from 18 to 21 , with an average age of 18.8 $(S D=0.622)$. The majority of the respondents were white $(78.40 \%, \mathrm{n}=98)$, while $8.00 \%(\mathrm{n}=10)$ were Hispanic, $7.20 \%(\mathrm{n}=9)$ were African American, 4.8\%(n=6) were Asian and $1.6 \%(\mathrm{n}=2)$ were in another racial category. 
For the second survey that was used to test the hypotheses and to answer the research questions, participants were recruited through Qualtrics Panels. In total, 290 participants took the survey, but responses from 61 participants were excluded through data screening and cleaning procedures, leaving a sample of 229 participants. The respondents were sampled with the following criteria: They had to be older than 18, live in the United States and speak English. An even distribution of men and women was also requested, but because some participants were omitted in the data cleaning process, the distribution of those who are left is slightly uneven as more women $(53.10 \%, \mathrm{n}=154)$ than $\operatorname{men}(46.90 \%, \mathrm{n}=136)$ were kept in the sample. The participants were considerably older than in the manipulation check, as the age ranged from 18 to 88 , with an average age of $52.85(S D=16.59)$. Most of the respondents were white $(87.24 \%$, $\mathrm{n}=253$ ), while only $5.86 \%$ were African-American $(\mathrm{n}=17), 4.83 \%$ were Hispanic $(\mathrm{n}=14), 1.03 \%$ were Asian $(\mathrm{n}=3)$ and $1.03 \%$ didn't identify their race $(\mathrm{n}=3)$.

As in the manipulation test, respondents' answers were changed to missing for a given scenario if they spent less than 30 seconds on a page, since this indicates they haven't read the stimuli before beginning to answer, and, if participants spent less than ten seconds from their first click on a survey to their last, their answers also were changed to missing for that scenario. Because some respondents' answers were changed to missing for given scenarios, each statistical model had a sample size that was lower than 229.

\section{Stimuli Development and Manipulation}

As stimulus materials, four organizational reputational crisis scenarios were created. In order to make the scenarios appear as realistic as possible, they were all based on real events, but 
details from the scenarios were slightly modified, and the crisis responses were completely modified for the purpose of this study, and. The participants were made aware of this, before taking the survey.

The four organizations involved in the scenarios were the American Red Cross, United Airlines, Hydrite Chemical Co. and Common Ground Storage. The American Red Cross scenario included a critical article describing how almost $\$ 500$ million that were raised after a hurricane hit Haiti in 2010, mostly have been wasted through mismanagement and questionable spending, and a new report asserted that the American Red Cross faced "constant upheaval" of staff in Haiti, a "pattern" of "botched delivery of aid" and "an overreliance on foreigners who could not speak French or Creole." The United Airlines scenario focused on an infamous situation that was caught on video where a doctor was bumped from an overcrowded plane, refused to leave and eventually was dragged screaming of the United Express Flight 3411 from Chicago to Louisville, Kentucky. Hydrite Chemical Co. is a chemical factory located in Terre Haute Indiana. A chemical leak from the factory sent "at least 15 people" to the hospital for observation and caused a nearby speedway track to be evacuated. Common Ground Storage is an independent storage company, who received some very harsh criticism on social media by a customer who claimed he was being scammed by the company.

The crisis scenarios and responses for each condition (authentic and accommodative, authentic and non-accommodative, non-authentic and accommodative or non-authentic and nonaccommodative) were initially written by the author and were then modified by a panel of doctoral students with backgrounds as professional journalists, a public relations practitioner, and a strategic communication researcher. They all provided feedback with the intention of 
manipulating the responses as much as possible in the desired directions. A total of four scenarios and 16 crisis responses were created.

\section{Independent Variables}

Authenticity. The crisis responses were written to be either in an authentic voice or in a non-authentic voice. Inspired by Shen and Kim's (2012) conceptualization of authenticity, the degree of authenticity was developed by using certain clues such as degree of formality, using first or third-person voice, apparent truthfulness, transparency, consistency with expected values and whether the stated intentions appeared genuine in the crisis response.

To measure if the crisis responses were as authentic or not authentic in the expected directions, two different operationalizations were used. The first was Shen and Kim's scale for Perceived Authentic Organizational Behavior, created from seven Likert-type questions, where the participants note the extent to which they agree with the following statements: (1) "This organization always tells the truth," (2) "I believe that this organization's actions are genuine, (3) "I feel that this organization is willing to admit to mistakes when they are made," (4) "I feel that this organization accepts and learns from mistakes," and (5) "I believe that this organization's behavior matches its core values."

As an additional measurement, three Likert-type questions from Molleda and Jain's (2013) suggested authenticity scale was used: (1) “The organization's messages are original,” (2) "I feel what the organization said was authentic," and (3) "The organization demonstrated sincere support for the cause." The authors' original scale contains more items, but they were not directly applicable for the crisis scenarios. 
Accommodation. The crisis responses were also written to reflect the organizations either being accommodative or non-accommodative in their crisis responses. This conceptualization was inspired the contingency theory of accommodation (Cameron, Cropp, \& Reber, 2001; Cancel et al., 1997, 1999; Jin \& Cameron, 2006) and the accommodative answers had the organizations take responsibility, actively seek to make amends, and take steps to avoid the issues arising again. The non-accommodative responses took no or only a very minimum of responsibility and did not actively seeks to make amends and did not present any clear steps to prevent the issues from repeating in the future.

To operationalize accommodation, Jin and Cameron's (2006) scale for action-based accommodation is used. It consists of five Likert-type questions where the respondents have to indicated how willing ("Completely unwilling" to "Strongly willing") they believe the organizations were to do each of the following: (1) "To yield to the public's demands," (2) "To agree to follow what the public proposed," (3) "To accept the publics' propositions," (4) "To agree with the public on future action or procedure," and (5) "To agree to try the solutions suggested by the public."

\section{Dependent Variables}

To test the listed hypotheses, this study involves four different dependent variables that all reflect different respective of crises outcomes. Crisis responsibility, organizational reputation, anger, and word-of-mouth intention. Each of the dependent variables is constructed from multiple item-instruments since this assures a more accurate measurement compared to only 
using a single measure (Churchill, 1979). The internal consistency of the items is tested using Cronbach's Alpha.

Crisis responsibility. Crisis responsibility refers to the degree to which the public attribute blame and perceives the organization in question to be responsible for a crisis (Coombs \& Holladay, 2002). It is assessed using a three-item scale for blame developed by Griffin, Babin, and Darden (1992). Participants agreed on seven-point Likert scales ranging from "Strongly disagree" to "Strongly agree." In the original use of the scale, a five-point Likert scale was used, but for this study, a seven-point Likert scale is used for consistency with the other measures. The three items are: "Circumstances, not the organization, are responsible for the crisis," "The blame for the crisis lies with the organization," (reverse coded) and "The blame for the crisis lies in the circumstances, not the organization." In the Red Cross scenario, the Cronbach alpha was .89, and in the United Airlines scenario, it was .87. Both are considered good and in line with previous studies using the scale, which had Cronbach's alphas ranging from .78 to .90 (Coombs, 1998, 2007; Coombs \& Holladay, 2002)

Organizational reputation. Organizational reputation refers to the public's perception of an organization's image following a crisis and is an assessment of the degree to which the source is concerned with the interests of others. The scale used to measure organizational reputation is an adaption of Coombs and Holladay's (1996) 10-item Organizational Reputation Scale, which in turn is based on McCroskey's 1966 scale reflecting the character of a speaker. Coombs and Holladay adjusted the original scale by changing the term "speaker" to "organization." To reduce the length of the survey, only five of the Likert-type items were included. They were (1) "The organization is concerned with the well-being of its publics," (reverse) (2) "The organization is basically dishonest," (3) "I do not trust the organization to tell the truth about the incident," (4) 
"Under most circumstances, I would be likely to believe what the organization says," (reverse) and (5) "The organization is NOT concerned with the well-being of its publics". For each of the statements, the participants had to indicate their degree of agreement on a seven-point Likert scale ranging from "Strongly disagree" to "Strongly agree."

In the Red Cross scenario, the Cronbach alpha was .93, and in the United Airlines scenario, it was .88. Previous studies using the ten-item scale had Cronbach alphas of .82 (Coombs \& Holladay, 1996) and .92 (Coombs, 1998), and a five-item version had a Cronbach alpha of .87 (Coombs \& Holladay, 2002).

Anger. Anger refers to the negative feelings the public hold against an organization following a crisis incident. Coombs and Holladay's (2007) three-item scale for anger is used. The respondents had to indicate their degree of agreement on a seven-point Likert scale ranging from "Strongly disagree" to "Strongly agree" about the following statements: "I feel annoyed toward the organization for what happened," "I do NOT feel angry toward the organization," and "Because of the incident, I feel angry at the organization" (reverse coded). In the Red Cross scenario, the scale had a Cronbach's alpha of .86, and in the United Airlines scenario, the Cronbach's alpha was .87. An earlier study had a Cronbach's alpha of .86 (Coombs, 2007).

Word-of-mouth intention. Word-of-mouth intention refers to the degree to which the public would recommend an organization following a crisis. It is measured using four item-scale developed by Brown et al. (2005). The participants were each asked to indicate on a seven-point scale ranging from "Extremely likely" to "Extremely unlikely" how likely they would be to do either of the following: (1) "I would encourage family members or relatives to support this organization," (2) "I would encourage friends to support this organization," (3) "I would recommend supporting this organization to someone who asked my advice," and (4) "I would 
say positive things about this organization to other people." In the Red Cross scenario, the scale had a Cronbach's alpha of .97, and in the United Airlines scenario, the Cronbach's alpha was .96. Both are reflecting very high degrees of internal consistency in the scales, which is in line with an earlier study using the scale (Park, 2011). 


\section{CHAPTER 5}

\section{RESULTS}

\section{Manipulation Check Results}

Independent $\mathrm{t}$-tests were used to test if the manipulations were perceived as intended. For the scenarios concerning Hydrite Chemical Co. and Common Ground Storage the intentionally authentic scenarios both scored higher than then non-authentic scenarios on both authenticity scales, but the differences were not statistically significant.

Using Shen and Kim's scales for authenticity, where a higher number denotes a greater degree of authenticity, to evaluate Common Ground Storage's crisis responses, the messages manipulated to be authentic $(M=4.04, S D=1.50)$ were indeed seen as more authentic than the non-authentic responses $(M=4.00, S D=1.29)$. However, this difference was not statistically significant in the t-test: $t(107)=-0.1302, p=.45$." A similar outcome was reached using Molleda's authenticity scale. Even though the authentic responses $(M=4.15, S D=1.68)$ were higher than the non-authentic responses $(M=3.94, S D=1.36)$, the difference was not significant: $t(107)=-0.6943$, $p=.24$.

The responses concerning Hydrite Chemical Co.'s crisis reaction showed similar results. On Shen and Kim's scale, the messages that were manipulated as authentic were on average seen as more authentic $(M=4.70, S D=1.30)$ than the non-authentic responses $(M=4.50, S D=1.20)$ but the difference was not statistically significant. And the same thing was evident using Molleda's scale. The authentic responses were again slightly higher $(M=4.99, S D=1.47)$ than the nonauthentic responses $(M=4.49, S D=1.41)$, but not enough to be significant at the .05 level of significance $t(104)=-1.0640, p=.15$. 
However, the manipulated authentic responses for the American Red Cross and United Airlines did provide the expected results. For the Red Cross, the manipulated authentic responses cover a significantly higher score $(M=4.45, S D=1.35)$ which indicates a more authentic impression, than the non-authentic response types $(M=3.50, S D=1.35)$ conditions: $t(110)=-$ 3.7042, $p<.001$. When using Molleda's scale, the same result was apparent, the authentic answers scored higher $(M=4.65, S D=1.40)$ than the non-authentic answers $(M=3.87, S D=1.41)$ conditions: $t(110)=-2.9291, p<.001$.

For the United Airlines scenario, there also were significant differences between their crisis responses. Measured by Shen and Kim's scale, the responses manipulated as authentic were seen as more authentic $(M=4.16, S D=1.44)$ than the non-authentic responses $(M=3.44$, $S D=1.40)$ conditions: $t(110)=-2.6814, p<.01$. A similar outcome was revealed when Molleda's scale was used. The authentic responses were higher $(M=4.41, S D=1.57)$ than the non-authentic responses $(M=3.46, S D=1.44)$ conditions $t(110)=-3.3585, p<.001$.

Table 5. 1. Means of Authenticity Scores by Message Type

\begin{tabular}{lll}
\hline Scenario and scale & Authentic message & Non-authentic message \\
\hline Common Ground - Kim and Shen & $4.04(1.50)$ & $4.00(1.29)$ \\
Common Ground - Molleda & $4.15(1.68)$ & $3.94(1.36)$ \\
Hydrite - Kim and Shen & $4.70(1.30)$ & $4.50(1.20)$ \\
Hydrite - Molleda & $4.99(1.47)$ & $4.49(1.41)$ \\
American Red Cross - Kim and Shen & $4.45(1.35)$ & $3.50(1.35)$ \\
American Red Cross - Molleda & $4.65(1.40)$ & $3.87(1.41)$ \\
United Airlines - Kim and Shen & $4.16(1.44)$ & $3.44(1.40)$ \\
United Airlines - Molleda & $4.41(1.57)$ & $3.46(1.44)$ \\
\hline
\end{tabular}
Note: Numbers in parentheses indicate standard deviations. 
For the accommodation measure, we see statistically significant differences in the expected directions for both Common Ground, Hydrite and United Airlines. Unfortunately, a part of the survey was not set up correctly, so there is not complete data on accommodation in response to the American Red Cross scenarios.

Table 5. 2. Mean of Accommodation Scores by Response Type

\begin{tabular}{lcc}
\hline Scenario & $\begin{array}{c}\text { Accommodating } \\
\text { Response }\end{array}$ & Advocating Response \\
\hline Common Ground & $4.71(1.28)$ & $3.24(1.44)$ \\
Hydrite & $4.82(1.43)$ & $4.22(1.51)$ \\
United Airlines & $4.52(1.43)$ & $4.03(1.60)$ \\
\hline
\end{tabular}

Note: Numbers in parentheses indicate standard deviations.

Tests of Hypotheses and Research Questions

A 2 (authenticity: high degree vs. low degree) x 2 (accommodation: high degree vs. low degree) between subjects ANOVA was conducted with authenticity and accommodation as between-subjects factors for the two scenarios, to test hypotheses 1 and 5, and to answer research question 1 all focusing on the relationships between authenticity, accommodation and crisis responsibility attribution.

H1: A crisis response that is authentic will lead to a lesser degree of crisis responsibility attribution than a crisis response that is not authentic will do.

H5: A crisis response that is accommodative will lead to a lesser degree of crisis responsibility attribution than a crisis response that is not authentic will do.

R1: Is there an interaction effect between the presence of authenticity and type of crisis response on crisis responsibility attribution? 
In the Red Cross scenario, a significant main effect of authenticity on attributed crisis responsibility was found, $F(1,186)=4.27 p<.05$. Authentic crisis responses led to lesser degrees of attributed crisis responsibility $(M=4.49, S D=1.61)$ than non-authentic crisis responses $(M=4.96, S D=1.60)$. However, there was no significant main effect between accommodation and crisis responsibility, $F(1,186)=.22, p=.64$. There was also no significant interaction between authenticity and accommodation on crisis responsibility attribution, $F(1,186)=1.32, p=.25$.

Figure 5.1. An Interaction Effect Between Authenticity and Accommodation on Crisis Responsibility Attribution in the Red Cross Scenario

\section{5}

\subsection{5}

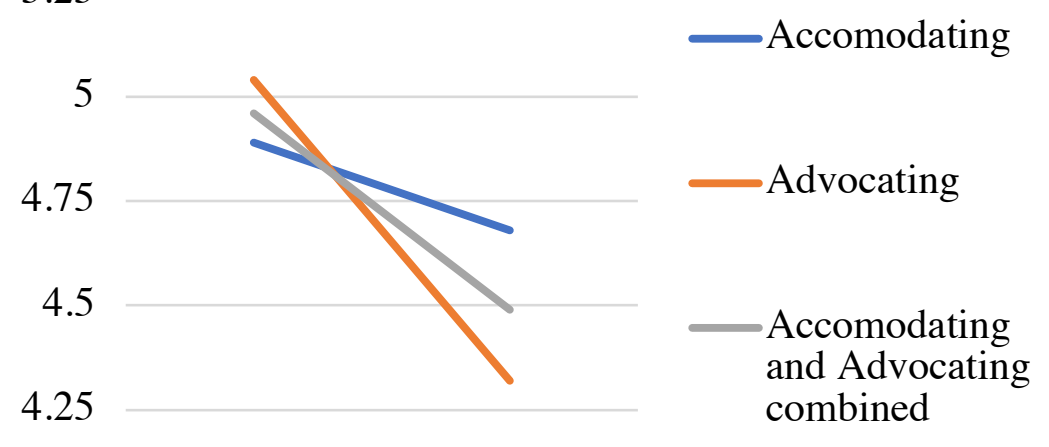

4

Non-Authentic Authentic

In the United Airlines scenario, similar findings appeared. A significant main effect of authenticity on attributed crisis responsibility was found, $F(1,191)=8.2 p<.01$. Authentic crisis responses led to lesser degrees of attributed crisis responsibility $(\mathrm{M}=5.23, S D=1.50)$ than nonauthentic crisis responses $(M=5.79, S D=1.20)$. And again, there was no significant main effect between accommodation and crisis responsibility, $F(1,191)=.10, p=.64$, and also no significant interaction between authenticity and accommodation on crisis responsibility attribution, $F(1$, 191) $=.18, p=.67$ 
Figure 5.2. An Interaction Effect Between Authenticity and Accommodation on Crisis Responsibility Attribution in the Red Cross Scenario

6.25

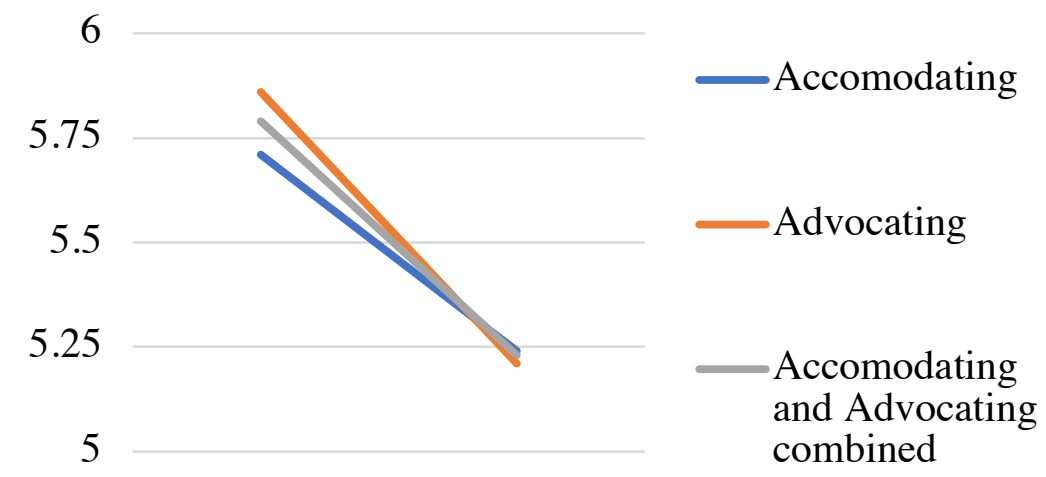

4.75

Non-Authentic Authentic

Table 5. 3. Means of Crisis Responsibility Attribution by Message and Response Type

\begin{tabular}{lcccc}
\hline & \multicolumn{2}{c}{ Red Cross } & \multicolumn{2}{c}{ United Airlines } \\
\cline { 2 - 5 } & $\begin{array}{c}\text { Non- } \\
\text { Authentic }\end{array}$ & Authentic & Authentic & Authentic \\
\hline Accommodating & $4.89(.20)$ & $4.68(.25)$ & $5.71(.19)$ & $5.24(.24)$ \\
Advocating & $5.04(.25)$ & $4.32(.22)$ & $5.86(.15)$ & $5.21(.20)$ \\
Accommodating and & $4.96(.15)$ & $4.49(.17)$ & $5.79(.12)$ & $5.23(.15)$ \\
$\quad$ advocating & & & & \\
\hline
\end{tabular}

Note: Numbers in parentheses indicate standard deviations.

Based on these results, $\mathrm{H} 1$ is supported, while $\mathrm{H} 5$ is rejected, and $\mathrm{R} 1$ can be answered with a no, since the interaction effects between authenticity and degree of accommodation on crisis responsibility attribution isn't significant in either scenario. However, it is worth noting that even though there isn't a statically significant interaction, then Figure 5.1, shows pattern of an interaction, as the advocating response is considerably more effective when delivered as part of an authentic message. 
$\mathrm{H} 2$ : A crisis response that is authentic will lead to a better organizational reputation than a crisis response that is not authentic will do.

H6: A crisis response that is accommodative will lead to a better organizational reputation than a crisis response that is not authentic will do.

R2: Is there an interaction effect between the presence of authenticity and type of crisis response on organizational reputation?

In the Red Cross scenario, a significant main effect of authenticity on organizational reputation was found, $F(1,186)=6.02 p<.05$. Authentic crisis responses led to a more positive perception of the organization's reputation $(M=4.06, S D=1.61)$ than non-authentic crisis responses $(M=3.52, S D=1.40)$. However, there was no significant main effect between accommodation and crisis responsibility, $F(1,186)=.23, p=.63$, and also no significant interaction between authenticity and accommodation on the organization's reputation, $F(1,186)=2.36, p=$ .13.

Figure 5.3. An Interaction Effect Between Authenticity and Accommodation on Organizational Reputation in the Red Cross Scenario

\section{5}

4.25

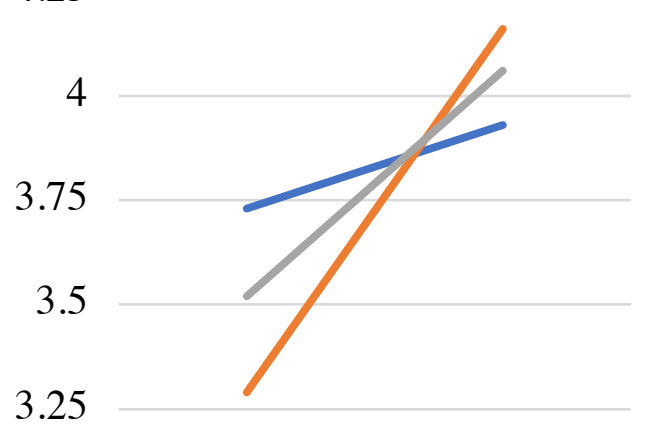

Accomodating

Advocating

Accomodating and Advocating combined

Non-Authentic Authentic 
In the United Airlines scenario, the findings are similar once more. A significant main effect of authenticity on organizational reputation was found, $F(1,191)=23.05 p<.001$. Authentic crisis responses led to better organizational reputation $(M=3.86, S D=1.41)$ than nonauthentic crisis responses $(M=2.92, S D=1.32)$. And again, there was no significant main effect between accommodation and organizational reputation, $F(1,191)=.2 .34$, $\mathrm{p}=.13$, and also no significant interaction between authenticity and accommodation on organizational reputation, $F(1,191)=.37, p=.55$.

Figure 5.4. An Interaction Effect Between Authenticity and Accommodation on Organizational Reputation in the United Airlines Scenario

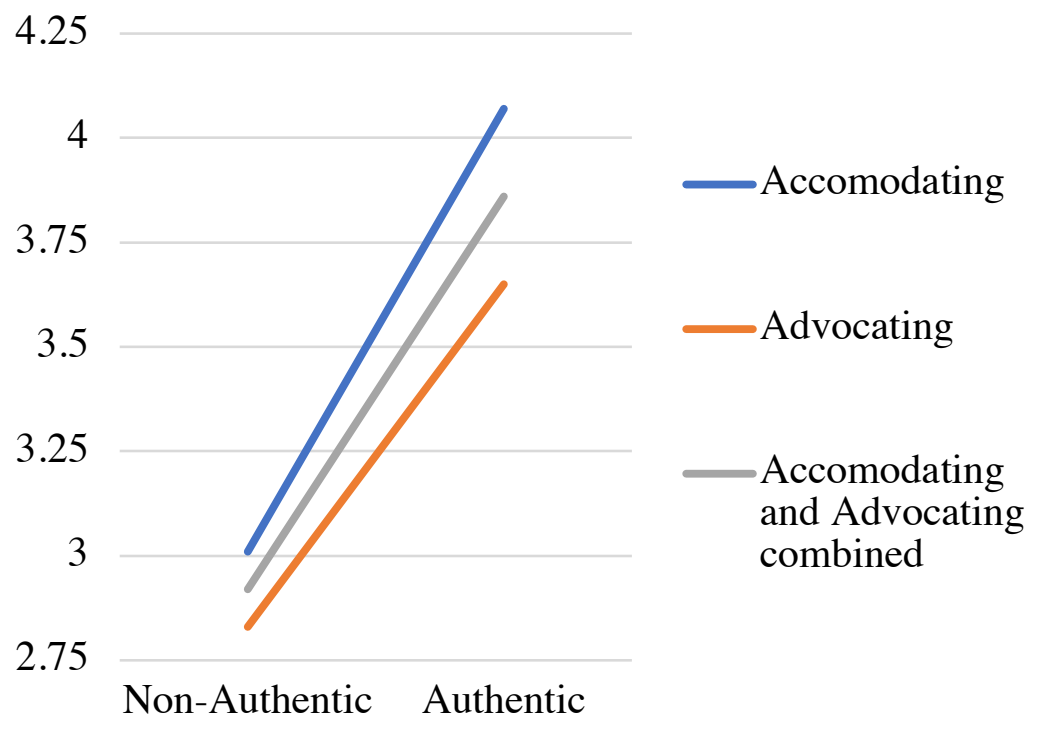

Table 5.4. Means of Organizational Reputation by Message and Response Type

\begin{tabular}{lcccc}
\hline & \multicolumn{2}{c}{ Red Cross } & \multicolumn{2}{c}{ United Airlines } \\
\cline { 2 - 5 } & $\begin{array}{c}\text { Non- } \\
\text { Authentic }\end{array}$ & Authentic & $\begin{array}{c}\text { Non- } \\
\text { Authentic }\end{array}$ & Authentic \\
\hline Accommodating & $3.73(.19)$ & $3.93(.27)$ & $3.01(.21)$ & $4.07(.19)$ \\
Advocating & $3.29(.20)$ & $4.16(.21)$ & $2.83(.16)$ & $3.65(.22)$ \\
$\begin{array}{l}\text { Accommodating and } \\
\text { advocating }\end{array}$ & $3.52(.14)$ & $4.06(.17)$ & $2.92(.13)$ & $3.86(.14)$ \\
\hline
\end{tabular}

Note: Numbers in parentheses indicate standard deviations. 
Based on these results, $\mathrm{H} 2$ is supported, while $\mathrm{H} 6$ is rejected, and $\mathrm{R} 2$ can be answered with a no since there doesn't appear to be any interaction effects between authenticity and degree of accommodation on organizational reputation. But again, there is the pattern of an interaction in the Red Cross scenario, as the advocating stance leads to higher organizational reputation when given as part of an authentic response, while the accommodating stance leads to a better organizational reputation when given as part of a non-authentic response.

H3: A crisis response that is authentic will lead to less anger than a crisis response that is not authentic will do.

H7: A crisis response that is accommodative will lead to less anger than a crisis response that is not authentic will do.

R3: Is there an interaction effect between the presence of authenticity and type of crisis response on anger following a crisis?

To test the two hypotheses and the research question focusing on the relationships between authenticity, accommodation and anger, another 2 (authenticity: high degree vs. low degree) x 2 (accommodation: high degree vs. low degree) between subjects ANOVA is conducted again with authenticity and accommodation as between subjects' factors on the two scenarios, but this time with anger as the dependent variable.

In the Red Cross scenario, a significant main effect of authenticity on anger was found, $F(1,186)=7.70, p<.01$. Authentic crisis responses led to less anger $(\mathrm{M}=3.51, S D=1.69)$ than non-authentic crisis responses $(\mathrm{M}=4.04, S D=1.42)$. However, there was no significant main effect between accommodation and anger, $F(1,186)=.00, p=.99$, and also no significant 
interaction between authenticity and accommodation on crisis responsibility attribution, $F(1$, $186)=1.19, p=.28$.

Figure 5.5 An Interaction Effect Between Authenticity and Accommodation on Anger in the Red Cross Scenario

\section{5}

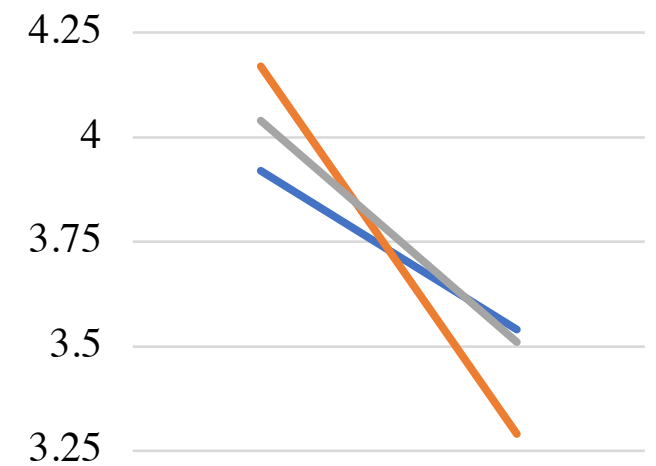

Accomodating

Advocating

Accomodating and Advocating combined

3

Non-Authentic Authentic

In the United Airlines scenario, the findings are similar once more. A significant main effect of authenticity on organizational reputation was found, $F(1,191)=11.17, p<.001$. Authentic crisis responses led to less anger $(\mathrm{M}=3.93, S D=1.57)$ than non-authentic crisis responses $(\mathrm{M}=4.64, S D=1.37)$. And again, there was no significant main effect between accommodation and anger, $F(1,191)=.1 .50, p=.22$, and also no significant interaction between authenticity and accommodation on crisis responsibility attribution, $F(1,191)=.30, p=.58$. 
Figure 5.6. An Interaction Effect Between Authenticity and Accommodation on Anger in the United Airlines Scenario

5

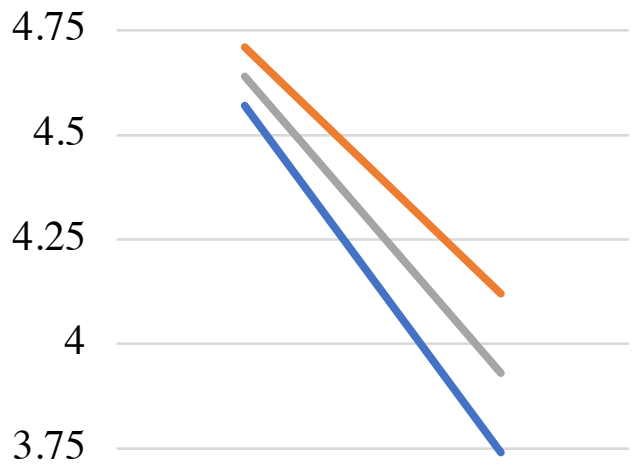

-Accomodating

—Advocating

-Accomodating and Advocating combined

3.5

Non-Authentic Authentic

Table 5. 5. Means of Anger by Message and Response Type

\begin{tabular}{lcccc}
\hline & \multicolumn{2}{c}{ Red Cross } & \multicolumn{2}{c}{ United Airlines } \\
\cline { 2 - 5 } & $\begin{array}{c}\text { Non- } \\
\text { Authentic }\end{array}$ & Authentic & $\begin{array}{c}\text { Non- } \\
\text { Authentic }\end{array}$ & Authentic \\
\hline Accommodating & $3.92(.20)$ & $3.54(.27)$ & $4.57(.21)$ & $3.74(.25)$ \\
Advocating & $4.17(.20)$ & $3.29(.23)$ & $4.71(.18)$ & $4.12(.20)$ \\
$\begin{array}{l}\text { Accommodating and } \\
\text { advocating }\end{array}$ & $4.04(.14)$ & $3.51(.18)$ & $4.64(.14)$ & $3.93(.16)$ \\
\hline
\end{tabular}

Note: Numbers in parentheses indicate standard deviations.

Based on these results, $\mathrm{H} 3$ is supported, while $\mathrm{H} 7$ is rejected, and $\mathrm{R} 3$ can be answered with a no since there doesn't appear to be any interaction effects between authenticity and degree of accommodation on anger following a crisis. But once more it should be noted that while it is not significant, there is a pattern of an interaction in the Red Cross scenario. 
H4: A crisis response that is authentic will lead to a greater intention of positively spreading word of mouth about an organization.

H8: A crisis response that is accommodative will lead to a greater intention of positively spreading word of mouth about an organization.

R4: Is there an interaction effect between the presence of authenticity and type of crisis response on the intention of positively spreading word of mouth about an organization following a crisis?

To test the two hypotheses and the research question focusing on the relationships between authenticity, accommodation and word-of-mouth intention, a final 2 (authenticity: high degree vs. low degree) x 2 (accommodation: high degree vs. low degree) between subjects ANOVA is conducted again with authenticity and accommodation as between subjects' factors on the two scenarios, but this time with worth of mouth intentions as the dependent variable.

In the Red Cross scenario, there are no significant main effects or interaction effects found. Among the participants, authentic messages caused slightly more positive word-of-mouth intentions $(M=2.67, S D=2.04)$ than non-authentic messages did $(M=2.17, S D=1.65)$. However, the results are not statistically significant at the .05 threshold $F(1,186)=3.23, p=.07$. There was also no significant main effect between accommodation and word-of-mouth intentions, $F(1,186)=.19, p=.67$, and also no significant interaction between authenticity and accommodation on word-of-mouth intentions, $F(1,186)=1.13, p=.29$. 
Figure 5.7. An Interaction Effect Between Authenticity and Accommodation on WOM-intention in the Red Cross Scenario

\subsection{5}

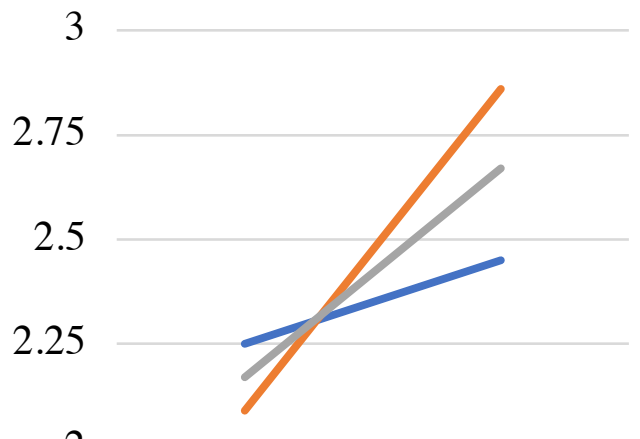

2

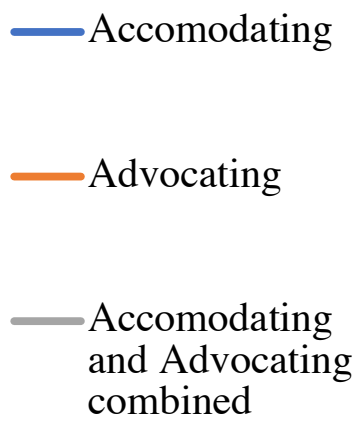

1.75

Non-Authentic Authentic

In the United Airlines scenario, a significant main effect of authenticity on organizational reputation was found, $F(1,191)=7.88, p<.01$. Authentic crisis responses led to greater word-ofmouth intentions $(M=4.97, S D=1.56)$ than non-authentic crisis responses $(M=5.58, S D=1.46)$. There was no significant main effect between accommodation and word-of-mouth intentions, $F(1,191)=.1 .91, p=.17$, and also no significant interaction between authenticity and accommodation on crisis responsibility attribution, $F(1,191)=.20, p=.65$. 
Figure 5.8. An Interaction Effect Between Authenticity and Accommodation on WOM-Intention in the United Airlines Scenario

\section{5}

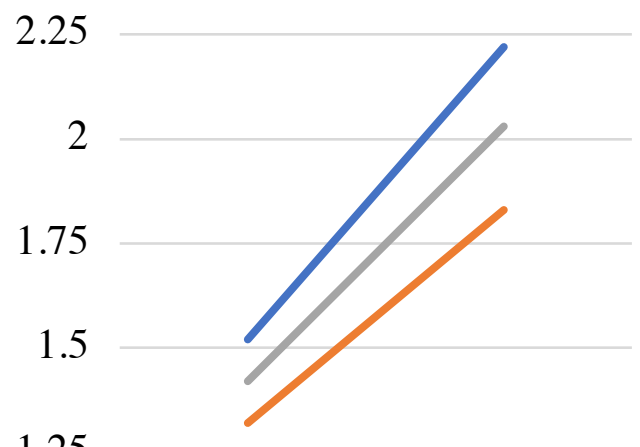

1.25
Accomodating

Advocating

Accomodating and Advocating combined

1

Non-Authentic Authentic

Table 5. 6. Means of WOM-Intention by Message and Response Type

\begin{tabular}{lcccc}
\hline & \multicolumn{2}{c}{ Red Cross } & \multicolumn{2}{c}{ United Airlines } \\
\cline { 2 - 5 } & $\begin{array}{c}\text { Non- } \\
\text { Authentic }\end{array}$ & Authentic & Non- & \\
& $2.25(.22)$ & $2.45(.30)$ & $1.52(.20)$ & $2.22(.23)$ \\
Accommonthen & Authentic \\
Advocating & $2.09(.25)$ & $2.86(.30)$ & $1.32(.15)$ & $1.83(.22)$ \\
Accommodating and & $2.17(.17)$ & $2.67(.21)$ & $1.42(.15)$ & $2.03(.16)$ \\
$\quad$ advocating & & & & \\
\hline
\end{tabular}

Note: Numbers in parentheses indicate standard deviations.

Based on these results, $\mathrm{H} 4$ is partially supported, while $\mathrm{H} 8$ is rejected, and R4 can be answered with a no since there doesn't appear to be any interaction effects between authenticity and degree of accommodation on word-of-mouth intentions following a crisis. But once more in the Red Cross scenario, there are patterns of an interaction effect showing the advocative responses growing in effectiveness compared to the accommodative responses, 


\section{CHAPTER 6}

\section{DISCUSSION}

The primary goal of this study was to explore how different degrees of authenticity and different levels of accommodation in a crisis response by an organization impacts how the public evaluates their handling of a crisis with regards to crisis responsibility attribution, organizational reputation, anger, and positive word-of-mouth intention. Also, of interest, was the question of whether there was an interaction effect between accommodation and authenticity. In other words, do authentic crisis responses work better when a company is accommodating to the stakeholders or when they are advocating their stance?

This research is extremely relevant today, because of what appears to be an ever-growing demand for authenticity (Lehman et al., 2019; Lim et al., 2015; Molleda \& Jain, 2013) and because public relations professionals increasingly emphasize authenticity as something to strive for in their communications between organizations and their publics (McDonald, 2016). This especially holds true on social media, where authenticity isn't only described as an option in organizational communication, but a necessity today (Men \& Tsai, 2016). Despite authenticity being the center of much debate, and a general agreement on crisis communication being one of the most vital assignments for public relations professionals (Coombs, 2007; Fearn-Banks, 2017), the role of authenticity on crisis communication outcomes has been noticeably absent in the strategic communication literature. Therefore, this paper set out to help remedy this, through a series of experiments. 


\section{Summary of Findings}

The first set of hypotheses tested the primary question of the study; whether authentic crisis responses leads to better crisis outcomes. It was tested on four different types of crisis outcomes for increased validity of the experiments. H1 posited that authentic crisis responses would lead to lesser degrees of crisis responsibility, and this was confirmed in both scenarios it was tested in. Those who saw authentic crisis responses were less likely to attribute responsibility for the crisis to the organization in question. $\mathrm{H} 2$ posited that authentic crisis responses would lead to a better organizational reputation of the organization in the crisis, and again, this was confirmed in both scenarios the respondents tested. Authentic crisis responses were positively associated with the respondents evaluating the organizational reputation positively. $\mathrm{H} 3$ posited that an authentic crisis response would lead to less anger among the respondents, and it was once more confirmed on both scenarios: Authentic crisis responses lead to lesser degrees of anger towards the organization caught up in the crisis. $\mathrm{H} 4$ posited that a crisis response that is authentic would lead to a greater intention of positively spreading word-ofmouth about an organization. This was only confirmed in one of the two scenarios. In the Red Cross scenario, authentic messages were associated with slightly more positive word-of-mouth intentions than non-authentic messages did, but the difference was not statistically significant at the .05 threshold. In the United Airlines scenario, the authentic messages were associated with more positive word-of-mouth intentions, and in this scenario, the difference was statistically significant. So overall, the results provided a clear indication of authenticity in crisis responses leading to more positive crisis communications outcomes. However, it should be noted that the average scores for the crisis communication outcomes all still indicate only a limited appreciation for the organizations, even for those who saw authentic responses. So while the 
authentic responses lead to more positive outcomes than the not-authentic responses, they don't completely eliminate the impact from the crisis scenarios.

The second set of hypotheses posited that being accommodative would have a positive impact on crisis outcomes. H5 suggested that greater accommodation would lead to lesser degrees of crisis responsibility attribution, H6 posited that greater accommodation would lead to better organizational reputation, $\mathrm{H} 7$ posited that greater accommodation would lead to less anger, and $\mathrm{H} 8$ posited that an accommodative response would lead to a greater likelihood to positively spreading the word-of-mouth about the organization in question. However, all four hypotheses were rejected in both scenarios. There was no significant evidence that being accommodative in these scenarios led to more positive crisis outcomes.

The four research questions asked whether there were any interaction effects between authenticity and accommodation on crisis responsibility attribution, organizational reputation, anger or word-of-mouth intentions. None of the ANOVAs provided any significant interaction of authenticity and accommodation on the crisis outcomes. However, it should be noted that in the Red Cross scenario, there were patterns of an interaction. For the responses that were not authentic, the accommodative responses led to the more positive crisis outcomes than the advocative responses, but for the authentic answers, it was the advocating responses that were associated with the most positive crisis outcomes. But as previously stated, these interactions were not significant at the .05 level, and also only appear in the Red Cross scenario. In the United Airlines scenario, there were no patterns of interactions. 


\section{Theoretical Implications}

An extensive scholarship in a wide array of fields such as branding, psychology, leadership management, interpersonal relationships, and political communication has proven that being authentic, or at least appearing to be authentic is beneficial under many circumstances.

In branding research, it has been established that when brands appear authentic, it leads to positive outcomes for them. The target groups show greater identification with the brand, the attachment is stronger, and the trust in the brand grows stronger as well. (Baker et al., 2014; Eggers et al., 2013; Morhart et al., 2015). In interpersonal relationship research, Kernis (2003) found that individuals that are seen as authentic also appear to have higher levels of self-esteem and are more likely to develop good relationships with others. In management literature, authentic leadership was found to be a predictor of job satisfaction and job performance (Walumbwa, Avolio, Gardner, Wernsing, \& Peterson, 2008). And in strategic communication research, it has been found that perceived authenticity by an organization causes its employees to be more likely to positively share the word about the organization (Mazzei et al., 2016), and that authenticity predicts positive organization-public relationships according to Shen and Kim (2012).

However, the question of whether communicating with authenticity also is effective when applied in crisis communication, a public relations subject that otherwise receives a great amount of scholarly attention, had not yet been tested quantitively. This study set out to add to the literature by testing this specific matter, and it found that, at least under the tested circumstances, authenticity does, in fact, lead to more positive crisis communication outcomes. Thereby, the findings confirm what has been theorized earlier, and the first small step of exploring the role of authenticity in crisis communication has been taken. This opens the door for a new set of 
questions: Under what circumstances is authenticity effective in crisis communication, and when is it not?

The results showed that whether a crisis response was authentic or not, was a stronger predictor of crisis success than if the organization took an accommodative or adversarial approach in their responses. The decision to accommodate or advocate has otherwise been proven extensively to impact crisis communication outcomes (Cameron et al., 2008; Cancel et al., 1999), so there is a reason to be optimistic about the impact of authenticity in crisis communication. However, it is highly unlikely that appearing perfectly authentic in all crisis responses is possible, and even if it is possible, then it might be more beneficial for strategic communication practitioners to aim for authentic crisis responses in some circumstances more than others.

\section{SCCT and the Challenges of Being Authentic During Intentional Cluster Crises}

In Coombs' Situational Crisis Communication Theory, a distinction is made between three types of organizational crises: victim clusters, that are crises caused by extraneous factors such as natural disasters, accidental clusters, that are crises caused by unintentional human errors by someone who are part of the organization, and intentional clusters, that are caused by misdeeds or excessive negligence by the organization in question. The crises in victim clusters pose the least grave threat to a company's reputation, and those in the intentional cluster pose the most severe threat to them. Both of the tested crisis scenarios here are examples of crises that were caused, or at least made significantly worse by the organizations' own actions and would, 
therefore, fall in the intentional cluster category, the one that poses the most serious reputational threats.

Communicating with authenticity in the intentional cluster scenarios would be particularly challenging since the organizations are responding from a position where their authenticity already has been compromised. The definition of authenticity used in this study focuses on three pillars: truthfulness, transparency, and consistency, and when responding to a crisis in the intentional cluster, organizations would be in situations where they are likely to have violated all three of these: They have not been true to themselves and their stated values while being negligent or doing the misdeeds that caused the crisis (one at least would assume); they, in most cases, would not have been transparent in their actions that led to the crisis; and the wrongdoing would also not be consistent with their stated values. Naturally, this would make it harder to convince an organization's stakeholders that the crisis response is authentic, even though their past behavior was not. Despite this, authenticity was found to have a real effect on crisis communication outcomes in the two the tested scenarios here, that both fell within the intentional crisis cluster scenario. So, based on this, there is a strong reason to be optimistic about the impact of authenticity on crisis communication outcomes. If authentic crisis messaging can have a measurable and positive effect when applied under the most difficult circumstances, then it should be an even more effective tactic when applied in response to crises that fall within the victim or accidental clusters, since it is assumed here that the publics would be more accepting of authentic responses. 


\section{Should authenticity be Adversarial or Accommodating?}

If the evidence of wrongdoing or negligence in an intentional cluster is convincing to the public, then it could be contended that the organization must accommodate to appear authentic. "If you clearly have done something wrong, and you claim to now be true and consistent to your stated values, then you must accommodate and take action to correct the wrongdoing. Otherwise, your crisis response is insincere and thus inauthentic," would be the argument. Additionally, for a crisis response to be perceived as authentic, there would need to be an aspect of transparency, and in many cases, being transparent would be seen as being part of an accommodative effort.

A contradictory argument would be that when the organizations are adversarial in their crisis responses, they are perceived to be consistent and to not give in to outside pressures, which is in line with being true to one self. By "swimming against the stream" - ignoring harsh criticism and pressure, and by refusing to accommodate - organizations show a willingness to stay true to their values and to be consistent, even though it potentially can come at a high price, something that is very strongly associated with authentic behavior. The advocating stance would therefore in effect highlight the authentic aspect and thus strengthen its impact. There is anecdotal evidence of this being the case for an organization faced by an accidental cluster crisis (Christensen, 2015), but only because they managed to credibly convince their key publics that the criticism aimed at them was inaccurate or unfair. And that specific aspect appears to be crucial. An organization can appear simultaneously authentic and adversarial in a crisis response, and the two tactics can strengthen each other, but only if the organization credibly convince the key stakeholders that it isn't at fault for the crisis. By failing to convince them of this, there is a real risk the choice of tactics instead will backfire and lead to less positive crisis outcomes. 
For this study, despite what appeared to be clear evidence of negligence and mishandling from the organizations in question in both crisis scenarios, no interaction effects between accommodation and authenticity was significant. Why that is, is open for interpretation. It could simply be that none of the suggested reasons for there being an interaction effect holds true, at least under the circumstances of this study. Or it could be a question of the two effects canceling each other out here. It would be highly relevant to explore this matter further in future research projects.

\section{Authenticity and the Contingency Theory of Accommodation}

In the contingency theory of accommodation, a series of external and internal variables are identified as indicators of where on the accommodation-advocacy continuum an organization should be in response to a crisis. Some of these factors might also predict the extent that it would be possible to appear authentic and whether it is beneficial to aim to be authentic in a given crisis response. The external factors that have been identified for the contingency theory of accommodation are grouped as threats, industry-specific environment, general political/social environment, external public characteristics, and the issue under consideration. (Cameron et al., 2001, 2008, Cancel et al., 1997, 1999). When evaluating the effectiveness possibility and effectiveness of delivering an authentic crisis response, all five groups of factors can be theorized to be relevant.

Threats are factors such as pending litigation, government regulation, damaging publicity to the organization's reputation and legitimizing activists' claims. All of these factors would impact the ability to be authentic and the effectiveness of the approach. The threat of potential litigation could put severe restrictions on how transparent an organization could be in a crisis response, as sharing all available information might lead to legal action. Being truthful and 
transparent about all aspects of a crisis might also lead to increased government regulation eventually, which can hinder the organization in the future. And by being completely truthful, transparent and consistent, even when it comes to information and actions that won't be well received among some stakeholders, an organization risks suffering non-repairable damage to their reputation, damage they would not have suffered through a less transparent approach. On the flip side, if an organization voluntarily releases information that is damaging to their reputation, the effects are less severe than if they had not been truthful and transparent and this information later becomes public (Fearn-Banks, 2017).

Industry-specific environmental factors, for example, the number of competitors and the levels of competition. Since consistency is a prerequisite of authenticity as defined here, the real consequence from an authentic response might not be immediate, but instead only appear later. In a highly competitive environment, waiting for the payoff might not always be possible, and competitors from even actively try to undermine an organization's authenticity efforts.

General political/social environment, for example, the degree of political and social support for the organization. This could have an impact in more than one way. It could be theorized that with broad political and social support, an organization would be more robust and therefore better equipped to be authentic in a crisis response, even if it potentially could come at a cost. On the other hand, it could also be theorized that if organizations do not have broad political or social support, it would actually be easier for them to stand out as authentic, since them being true to their values and consistent in their actions comes at a price and therefore is more noticeable. The Make-a-Wish foundation might be just as true to their values and consistent as Planned Parenthood, but because the former's mission of providing relief for critically ill kids and their parents is universally supported, fewer would take notice or think of 
them being strikingly true to their values and consistent when they communicate messages in support of that. For Planned Parenthood, on the other hand, being true and consistent to their values comes at a price among some political and social stakeholders, so it is considerably more noticeable when it happens, and they would, therefore, stand out as more authentic.

External public characteristics, such as the number of members of the public in question, the credibility of the source, past successes and failures of groups to evoke change, the amount of advocacy the organization practices and the involvement of its members. All of these factors could impact whether it is possible to be authentic and how effective it would be in a crisis situation. If a message is truthful, transparent and consistent, but not immediately popular, it might be easier to reach and convince a smaller concentrated public than a larger one about the values and points of view that the sender is trying to communicate, especially if it is a more complex issue. The source a message is communicated in would also make a difference. It can, for example, be conceived that an organization would appear more authentic by having a spokesperson appear in an on-camera interview with a critical journalist known for asking critical questions, than if they were to simply release a statement, for two reasons. More cues on authenticity cues can be communicated through a visual media than a written statement, and by only releasing the statement and not offering opportunities for questions that clarify or test their statements, stakeholders might feel that the organization is not being completely truthful and transparent, even if they actually were.

The issue under consideration, for example, the size, the stake, and the complexity of the issue that has caused the crisis. Again, there is a reason to believe that these factors impact the possibility and effectiveness of an authentic crisis response. A crisis of a large magnitude does not only provide a bigger risk to the organization in question, but it also invites more attention 
from publics, media, and other stakeholders. This could affect the impact of authenticity in multiple ways. The greater attention means that it is more likely to be revealed if the communication hasn't been truthful, transparent, and consistent. It would also mean a greater likelihood for the publics to pay prolonged attention to the issue at hand and therefore, they could over time notice a consistency in the communication, something that theoretically should strengthen the impact of authenticity. Finally, there is a reason to believe that the complexity of the matter is relevant too. If an issue causing a crisis is too complex, then it can be posited that some stakeholders would experience the crisis response as less transparent and perhaps even less truthful too. If certain stakeholders don't understand the issue, they might believe the lack of understanding is because of incomplete or inaccurate information, or that the organization intentionally made the issue complex, so it was harder to attribute crisis responsibility. On the other hand, there is also anecdotal evidence of being authentic and persistent can be a way to eventually explain and convince the publics regarding a complex issue that threatened an organization's reputation (Christensen, 2015).

There is also reason to believe that the internal factors determining whether an organization should accommodate or advocate in a conflict situation that was identified by Cancel et al., have an impact on the viability and appropriateness of communicating with authenticity in crisis situations. The groups of internal factors that have been identified are general corporate/organizational characteristics, characteristics of the public relations department, top management characteristics, internal threats, personality characteristics of involved organization members, and relationship characteristics

Characteristics of the organization cover a wide range of factors. For example, if it is centralized geographically or not, how old organization is and the value that is placed on 
tradition, the degree of economic stability in the organization, the corporate culture, and other issues the organization have currently or have had in the past. If an organization is centralized with a stronger presence in one area, the local stakeholders might feel a stronger connection with the organization, and thus more likely to accept any communication as truthful, transparent and consistent. On the flipside, there would also be increased attention to a local organization's crisis responses, so they would face more scrutiny. The age of an organization combined with the emphasis on tradition could also be a determining factor in whether authentic communication is effective. If the organization has a long history of acting in accordance with their values and this has been emphasized beforehand, then the stakeholders would be more willing to accept that a new statement is consistent with their values. An economically stable organization would also be better equipped to "play it cool" and act in a way that is authentic with its values, despite outside pressures because they better can handle any short-term negative feedback than a less stable organization could.

\section{Characteristics of the public relations department, the individual public relations}

practitioners and top management, such as the qualifications of the public relations staff, the experience levels of dealing with conflict, the general communication competency in the public relations department, the potential to practice various public relations scenarios, the location of the public relations department in the organizational hierarchy, funding and time available to deal with external publics, and management's support of the public relations department . How qualified, experienced, and prepared a public relations department and its members are in dealing with crisis scenarios will all impact the degree to which it is possible and effective to make an authentic crisis response. For communication to be perceived as authentic, it needs to be well constructed, and without mistakes, since any violation of the truthfulness, transparency, and 
consistency in the message would backfire and make the organization appear less authentic than before. The location of the public relations department in the organizational hierarchy also matters when trying to achieve authenticity. If there is a disconnect between the public relations department and management, it can undermine any effort to be authentic. If the management level provides wrong or incomplete information to the public relations department, then it would be impossible for them to communicate in a truthful and transparent manner. And if management does not make sure that efforts are taken to follow through on any statements released by the public relations department, then the communicative efforts will appear less consistent and thus less authentic.

Internal threats, such as the economic considerations in the organization, marring of employees and stockholders' perception of the organization, and the marring of the personal reputation of the company decision makers. Considerations of whether implementing a certain strategy will lead to a potential financial loss or gain for an organization, is that much of crisis communication boils down to. However, from an authenticity perspective, this presents somewhat of a paradox. It has been established in this study that being authentic when responding to a crisis can lead to more positive crisis outcomes, which in turn limits the financial cost of the reputational crises (Coombs, 2014; Fearn-Banks, 2017). But one way to appear more authentic is to act in accordance with ones stated values, even if it comes at a financial gain. So, making decisions that go against what appears to best financially, could actually be beneficial, but there is another layer to this paradox. Because if it is perceived that an entity is trying to be authentic for inauthentic reasons (such as profit), then they will appear even less authentic than if they had not made any attempt at all (Kernis \& Goldman, 2006). 
Characteristics of organization-public relationships, such as the trust between an organization and its external publics, the dependency of the parties involved, and any ideological barriers that may exist between the organization and its publics. The trust the public hold in an organization can be a defining factor when evaluating if it is possible and viable to use authenticity in a crisis response. If a good amount of trust already exists, then it would naturally be easier to convince the public that the sender really is truthful, transparent, and consistent, than if the public were had little or no trust in them. Likewise, ideological barriers between the public and they could make it harder to appear authentic. Political communication research shows that we are more likely to believe those we agree ideologically with than those we don't agree with. So, a crisis response would be met with considerably more skepticism and would appear less authentic, if there were ideological barriers between the organization sending the message and the public receiving it.

\section{Practical Implications}

This research revealed insights that can be valuable for public relations professionals who have to deal with a crisis situation in the future. It is clear than aiming for authenticity in a crisis response can be an effective strategy, and under the tested circumstances it actually turned out to be a stronger predictor for crisis success than whether the organization an accommodating or advocating stance to the crisis. This is an insight that can help guide practitioners' communication in the future. It would have been further beneficial to practitioners if the results significantly indicated whether the authentic messages were most effective when the organization was accommodating or not accommodating to crisis responses, but unfortunately, the experiments provided no clear evidence in either direction for this. 
Learning more about how organizations can appear as authentic as possible in their communication can pay large dividends financially, and not only when a reputational crisis threatens, but also if they are tested by other challenges. Fombrun and van Riel (2003) argue that when financial markets crash, firms that have a reputation for being authentic are likely to experience less financial volatility compared to their competitors.

For public relations practitioners, it would be very beneficial if future research efforts focused on discovering insights about the more specific circumstances where authenticity can make a positive difference, and the steps that can be taken to appear as authentic as possible.

\section{Limitations and Future Research}

Like most other experiments testing the effects of crisis communications, this study has some concerns related to the external validity of the experiment. Here, the cases were real, but the respondents had been warned ahead of time that the crisis responses were manipulated. Furthermore, the crisis scenarios and responses were both presented as online news articles; they were still in a somewhat contrived setting where they were part of an online research survey. This might have led to different outcomes than if the scenarios were presented in setting similar to where the respondents normally get informed about current events, for example in their social media feeds or as part of their preferred news outlets they have a greater trust in, so they, therefore, would be more likely to accept the information at face value.

Another limitation of this experiment and one apparent in virtually all other crisis communication experiments with very few exceptions is that it only reflects a snapshot of the crisis communication process and a non-mediated response. However, in reality, crisis 
communication is a negotiated process that plays out over a period of time (Fearn-Banks, 2017), and the real impact of a crisis response might only be apparent years after the event. In United Airways' case, the most relevant parameter for successful crisis communication would not necessarily be the crisis responsibility attribution, organizational reputation or anger among its key publics immediately after the crisis response, but instead the degree to which potential customers had forgotten or forgiven the company's bad handling of the situation three months later. In a more recent example, this was evident when Nike launched a campaign starring former NFL player Colin Kaepernick in January 2019. Because of Kaepernick's activism and prior refusal to stand during the national anthem, the ad was met with a mix of criticism and praise on social media and on key stakeholders. In the immediate aftermath, the critics appeared to be more influential than the supporters of the ad, something that was reflected through public opinion polls and a drop in the company's stock value. However, later, public opinion changed to being overwhelmingly in support of Nike and Kaepernick.

It is not the passing of time alone that impacts changes in how a crisis is evaluated by the public, but instead a slew of extraneous factors. The perhaps most important of these is how the message is mediated. Very few citizens would only see a crisis response reported neutrally or directly from the organization in question. Instead, it would usually appear as part of broader reporting on the subject where reactions to the crisis response from critics as well as additional context are added to the reporting, and additional reporting would follow with new angles to that either can strengthen or weaken the organization's position. And the competitive market place means that organizations also risk being faced with counterclaims from competitors (Goldman \& Papson, 1998). This is especially important to keep in mind when evaluating the authenticity aspect of a crisis response, since a key aspect of authentic communication, is whether that which 
is perceived authentic stands the test of time and challenging arguments. "If you say you're authentic, then you'd better be authentic" as Gilmore and Pine argued (2007, p. 90), and additional coverage would allow greater opportunity to expose a message as being less authentic.

Furthermore, media consumers use a wide range of media to pursue information about current affairs (Livingstone, 2005) and are actively looking for cues from gatekeepers and influencers about how they should feel about the information they are presented. Earlier studies have found anecdotal evidence of influencers changing public opinion of an organization by sharing and commenting on the organization's crisis response (Christensen, 2015), so it would be of great interest to explore this issue further by testing the impact of certain influencers approving, or disapproving, authentic crisis messages.

The respondents for this study were recruited through Qualtrics Panels, and while they were not specifically identified as belonging in a specific single stakeholder group, it was assumed they were part of the public and potential customers and donors to the organizations. However, Walker (2010) found that corporations can have multiple reputations that vary by stakeholder groups, since each group evaluates the organization differently, so for a future research project, it would be relevant to test if the crisis messages are perceived differently among different stakeholder groups.

This study failed to find any significant interaction effects between authenticity and whether an organization is accommodating or advocating. But while the United Airlines scenario showed no signs of interaction effects, the Red Cross scenario revealed not-significant patterns of an interaction effect, indicating that advocacy combined with authenticity leads to more positive crisis communication outcomes. A study with more participants might find this relationship to actually be statistically significant. If that is the case, it would be interesting to 
explore this further: Why is there a pattern of an interaction effect in the Red Cross scenario but not for the United Airlines? Is it because of the circumstances surrounding the crises? One could make the argument that in the Red Cross scenario, it is not as clear who is at fault as in the United Airlines scenario. So while it would be possible to be advocating and authentic for the Red Cross, United Airlines cannot do the same, without appearing untrustworthy, because of the circumstances of the crisis. This calls for additional research, to explore if there actually are interactions between authenticity and accommodation/advocacy, and if so, under which circumstances do these take place? 


\section{REFERENCES}

Baker, T. L., Rapp, A., Meyer, T., \& Mullins, R. (2014). The role of brand communications on front line service employee beliefs, behaviors, and performance. Journal of the Academy of Marketing Science, 42(6), 642-657.

Beverland, M. B. (2005). Crafting brand authenticity: The case of luxury wines. Journal of Management Studies, 42(5), 1003-1029.

Boin, A., Hart, Paul 't, \& Kuipers, S. (2018). The crisis approach. In Handbook of Disaster Research (pp. 23-38). Springer.

Boyle, D. (2004). Authenticity: Brands, fakes, spin and the lust for real life. HarperCollins. UK.

Brown, T. J., Barry, T. E., Dacin, P. A., \& Gunst, R. F. (2005). Spreading the Word: Investigating Antecedents of Consumers' Positive Word-of-Mouth Intentions and Behaviors in a Retailing Context. Journal of the Academy of Marketing Science, 33(2), 123-138. https://doi.org/10.1177/0092070304268417

Cameron, G. T., Cropp, F., \& Reber, B. H. (2001). Getting past platitudes: Factors limiting accommodation in public relations. Journal of Communication Management, 5(3), 242261.

Cameron, G. T., Wilcox, D. L., Reber, B. H., \& Shin, J.-H. (2008). Public relations today: Managing competition and conflict. Allyn \& Bacon, Boston.

Cancel, A. E., Cameron, G. T., Sallot, L. M., \& Mitrook, M. A. (1997). It depends: A contingency theory of accommodation in public relations. Journal of Public Relations Research, 9(1), 31-63.

Cancel, A. E., Mitrook, M. A., \& Cameron, G. T. (1999). Testing the contingency theory of accommodation in public relations. Public Relations Review, 25(2), 171-197. 
Chiu, H.-C., Hsieh, Y.-C., \& Kuo, Y.-C. (2012). How to align your brand stories with your products. Journal of Retailing, 88(2), 262-275.

Churchill, G. A. (1979). A Paradigm for Developing Better Measures of Marketing Constructs. Journal of Marketing Research, 16(1), 64-73.

Coombs, W. T. (1998). An Analytic Framework for Crisis Situations: Better Responses From a Better Understanding of the Situation. Journal of Public Relations Research, 10(3), 177191.

Coombs, W. T. (2007). Protecting organization reputations during a crisis: The development and application of situational crisis communication theory. Corporate Reputation Review, $10(3), 163-176$.

Coombs, W. T. (2014). Ongoing Crisis Communication: Planning, Managing, and Responding: Planning, Managing, and Responding.

Coombs, W. T., \& Holladay, S. J. (1996). Communication and Attributions in a Crisis: An Experimental Study in Crisis Communication. Journal of Public Relations Research, $8(4), 279-295$.

Coombs, W. T., \& Holladay, S. J. (2002). Helping Crisis Managers Protect Reputational Assets: Initial Tests of the Situational Crisis Communication Theory. Management Communication Quarterly, 16(2), 165-186.

Coombs, W. T., \& Holladay, S. J. (2011). An exploration of the effects of victim visuals on perceptions and reactions to crisis events. Public Relations Review, 37(2), 115-120.

Deibert, A. (2019, April 15). Why Authenticity In Marketing Matters Now More Than Ever. Retrieved April 15, 2019, from Forbes website: 
https://www.forbes.com/sites/forbescommunicationscouncil/2017/05/26/why-

authenticity-in-marketing-matters-now-more-than-ever/

Dutton, D. (2003). Authenticity in art. The Oxford Handbook of Aesthetics, 258-274.

Edwards, L. (2010). Authenticity in organisational context: fragmentation, contradiction and loss of control. Journal of Communication Management, 14(3), 192-205.

Eggers, F., O’Dwyer, M., Kraus, S., Vallaster, C., \& Güldenberg, S. (2013). The impact of brand authenticity on brand trust and SME growth: A CEO perspective. Journal of World Business, 48(3), 340-348.

Fearn-Banks, K. (2017). Crisis communications: A casebook approach. Routledge.

Fine, G. A. (2003). Crafting authenticity: The validation of identity in self-taught art. Theory and Society, 32(2), 153-180.

FleishmanHillard. (2015, February 4). 2015: The Year of Authenticity. Retrieved April 15, 2019, from FleishmanHillard website: https://fleishmanhillard.com/2015/02/socialinnovation/2015-year-authenticity/

Fombrun, C. J., Van Riel, C. B., \& Van Riel, C. (2004). Fame \& fortune: How successful companies build winning reputations. FT Press.

Frosh, P. (2001). To thine own self be true: The discourse of authenticity in mass cultural production. The Communication Review, 4(4), 541-557.

Füller, J., Schroll, R., \& von Hippel, E. (2013). User generated brands and their contribution to the diffusion of user innovations. Research Policy, 42(6-7), 1197-1209.

Gilmore, J. H., \& Pine, B. J. (2007). Authenticity: What Consumers Really Want. Harvard Business School Press. 
Gilpin, D. R., Palazzolo, E. T., \& Brody, N. (2010). Socially mediated authenticity. Journal of Communication Management, 14(3), 258-278.

Griffin, M., Babin, B. J., \& Darden, W. R. (1992). Consumer Assessments of Responsibility For Product-Related Injuries: the Impact of Regulations, Warnings, and Promotional Policies. ACR North American Advances, NA-19. Retrieved from http://acrwebsite.org/volumes/7404/volumes/v19/NA-19

Heath, R. L., \& Palenchar, M. J. (2008). Strategic issues management: Organizations and public policy challenges. Sage Publications.

Henderson, A., \& Bowley, R. (2010). Authentic dialogue? The role of "friendship" in a social media recruitment campaign. Journal of Communication Management, 14(3), 237-257.

Hoffman, J. D. (1993). The organizational climate of middle schools and dimensions of authenticity and trust (Doctoral dissertation, Rutgers University).

Holt, D. B. (2002). Why do brands cause trouble? A dialectical theory of consumer culture and branding. Journal of Consumer Research, 29(1), 70-90.

Jin, Y., \& Cameron, G. T. (2006). Scale development for measuring stance as degree of accommodation. Public Relations Review, 32(4), 423-425.

Kelleher, T. (2008). Organizational contingencies, organizational blogs and public relations practitioner stance toward publics. Public Relations Review, 34(3), 300-302.

Kelleher, T. (2009). Conversational voice, communicated commitment, and public relations outcomes in interactive online communication. Journal of Communication, 59(1), 172188. 
Kelleher, T., \& Miller, B. M. (2006). Organizational blogs and the human voice: Corporate blog strategies and relational outcomes. Journal of Computer-Mediated Communication, 11(2).

Kennick, W. E. (1985). Art and inauthenticity. The Journal of Aesthetics and Art Criticism, $44(1), 3-12$.

Kernis, M. H., \& Goldman, B. M. (2006). A multicomponent conceptualization of authenticity: Theory and research. Advances in Experimental Social Psychology, 38, 283-357.

Ki, E. J., \& Khang, H. (2005). The status of public relations research in the public relations leading journals between 1995 and 2004. Conference Paper Presented to the Public Relations Division of the Association for Education in Journalism and Mass Communication, Toronto, Canada.

Kim, J. Y., Kiousis, S., \& Molleda, J.-C. (2015). Use of affect in blog communication: Trust, credibility, and authenticity. Public Relations Review, 41(4), 504-507.

Kovács, B., Carroll, G. R., \& Lehman, D. W. (2017). The perils of proclaiming an authentic organizational identity. Sociological Science, 4, 80-106.

Lee, B. K. (2005). Crisis, culture, community. I PJ Kalbfleisch (red.), Communication Yearbook 29 (s. 275-309). Mahwah, NJ: Lawrence Earlbaum.

Lee, Betty Kaman. (2004). Audience-oriented approach to crisis communication: A study of Hong Kong consumers' evaluation of an organizational crisis. Communication Research, $31(5), 600-618$.

Lehman, D. W., O’Connor, K., Kovacs, B., \& Newman, G. E. (2019). Authenticity. Academy of Management Annals, 13(1), 1-42. 
Lim, J. S., Nicholson, J., Yang, S.-U., \& Kim, H.-K. (2015). Online authenticity, popularity, and the "Real Me" in a microblogging environment. Computers in Human Behavior, 52, 132143.

Margaretten, M., \& Gaber, I. (2012). The crisis in public communication and the pursuit of authenticity: An analysis of the Twitter feeds of Scottish MPs 2008-2010. Parliamentary Affairs, 67(2), 328-350.

Mazzei, A., Lee, Y., Togna, G., \& Kim, J.-N. (2016). The Impact of Perceived Authenticity and Employees' Empowerment on Communicative Behavior: An Integrated Model of Positive Megaphoning. The Impact of Perceived Authenticity and Employees' Empowerment on Communicative Behavior: An Integrated Model of Positive Megaphoning. Presented at the International Public Relations Research Conference. McDonald, C. J. (2016). We're Friends Right? Dialogical Strategy Effects in CSR Facebook Posts on Perceived Organizational Trust and Authenticity.

Men, L. R., \& Tsai, W.-H. S. (2014). Perceptual, attitudinal, and behavioral outcomes of organization-public engagement on corporate social networking sites. Journal of Public Relations Research, 26(5), 417-435.

Men, L. R., \& Tsai, W.-H. S. (2016). Public engagement with CEOs on social media: Motivations and relational outcomes. Public Relations Review, 42(5), 932-942.

Molleda, J.-C. (2009). Construct and dimensions of authenticity in strategic communication research. Anagramas-Rumbos Y Sentidos de La Comunicación-, 8(15), 85-97.

Molleda, J.-C., \& Jain, R. (2013). Testing a perceived authenticity index with triangulation research: The case of Xcaret in Mexico. International Journal of Strategic Communication, 7(1), 1-20. 
Montgomery, M. (2001). The uses of authenticity:"Speaking from experience” in a UK election broadcast. The Communication Review, 4(4), 447-462.

Morhart, F., Malär, L., Guèvremont, A., Girardin, F., \& Grohmann, B. (2015). Brand authenticity: An integrative framework and measurement scale. Journal of Consumer Psychology, 25(2), 200-218.

Napoli, J., Dickinson, S. J., Beverland, M. B., \& Farrelly, F. (2014). Measuring consumer-based brand authenticity. Journal of Business Research, 67(6), 1090-1098.

Park, H. (2011). Social Presence and Source Credibility in Blog-mediated Crisis Communication (PhD Thesis). University of Missouri-Columbia.

Park, H., \& Cameron, G. T. (2014). Keeping It Real Exploring the Roles of Conversational Human Voice and Source Credibility in Crisis Communication via Blogs. Journalism \& Mass Communication Quarterly, 1077699014538827.

Pearson, C. M., \& Clair, J. A. (1998). Reframing crisis management. Academy of Management Review, 23(1), 59-76.

Peterson, R. A. (2005). In search of authenticity. Journal of Management Studies, 42(5), 10831098.

Potter, A. (2011). The authenticity hoax: How we get lost finding ourselves. Emblem Editions.

Seeger, M. W., Sellnow, T. L., \& Ulmer, R. R. (1998). Communication, organization, and crisis. Annals of the International Communication Association, 21(1), 231-276.

Shapiro, M. A. (2002). Generalizability in communication research. Human Communication Research, 28(4), 491-500.

Shen, H., \& Kim, J.-N. (2012). The authentic enterprise: Another buzz word, or a true driver of quality relationships? Journal of Public Relations Research, 24(4), 371-389. 
Short, J., Williams, E., \& Christie, B. (1976). The social psychology of telecommunications.

Sisson, D. C., \& Bowen, S. A. (2017). Reputation management and authenticity: A case study of Starbucks' UK tax crisis and “\# SpreadTheCheer” campaign. Journal of Communication Management, 21(3), 287-302.

Sohn, Y. J., \& Lariscy, R. W. (2014). Understanding reputational crisis: Definition, properties, and consequences. Journal of Public Relations Research, 26(1), 23-43.

Spiggle, S., Nguyen, H. T., \& Caravella, M. (2012). More than fit: Brand extension authenticity. Journal of Marketing Research, 49(6), 967-983.

Thompson, C. J., Rindfleisch, A., \& Arsel, Z. (2006). Emotional branding and the strategic value of the doppelgänger brand image. Journal of Marketing, 70(1), 50-64.

Trilling, L. (1972). Sincerity and Authenticity. Cambridge, Mass.: Harvard University Press.

Walumbwa, F. O., Avolio, B. J., Gardner, W. L., Wernsing, T. S., \& Peterson, S. J. (2008). Authentic leadership: Development and validation of a theory-based measure. Journal of Management, 34(1), 89-126.

Zickmund, S. (2007). Deliberation, phronesis, and authenticity: Heidegger's early conception of rhetoric. Philosophy and Rhetoric, 40(4), 406-415. 


\section{APPENDIX A - EXPERIMENTAL STIMULI}

\section{Red Cross Crisis Scenario}

\section{Questions Arise About the Red Cross' \$500 Million In Haiti Relief}

When a devastating earthquake leveled Haiti in 2010, millions of people donated to the American Red Cross. The charity raised almost half a billion dollars. It was one of its most successful fundraising efforts ever.

The American Red Cross vowed to help Haitians rebuild, but after five years the Red Cross' legacy in Haiti is not new roads, or schools, or hundreds of new homes. It's difficult to know where all the money went.

NPR and ProPublica went in search of the nearly $\$ 500$ million and found a string of poorly managed projects, questionable spending and dubious claims of success, according to a review of hundreds of pages of the charity's internal documents and emails, as well as interviews with a dozen current and former officials.

The investigation asserted that the Red Cross faced "constant upheaval" of staff in Haiti, a "pattern" of "botched delivery of aid" and "an overreliance on foreigners who could not speak French or Creole."

The Red Cross also lacked expertise to carry out its own projects in Haiti and instead gave donors' money to other groups to do the work, escalating costs of overhead and management, which in one case added up to a third of a project's budget, the news outlets said in their account published Wednesday. 
The outlets also cited a 2013 U.S. Government Accountability Office report that found a Red Cross-USAID partnership to build homes didn't develop "because of the delays in securing land title and because of turnover in Red Cross leadership that resulted in shifting approaches to housing in Haiti," the GAO study said.

Red Cross Response. Condition: Authentic and Accommodating

Following the report, the President and CEO of the American Red Cross, Gail J.

McGovern, released the following statement:

"While I feel the recent investigative report by ProPublica/NPR suffered from a lack of balance, context and accuracy, it still made it clear that there is room for improvements in our work. Any dollar wasted on mismanagement or overpriced projects could have provided direct relief to the Haitians, so therefore I am personally disappointed whenever such an instance occurs.

Therefore, I will now initiate a thorough review of all our rebuilding efforts in Haiti. While I feel confident that the episodes of mismanagement are unfortunate exceptions out of countless successful projects, it is important that we get to the bottom of this, and swift action will be taken whenever necessary."

Red Cross Response. Condition: Authentic and not Accommodating

Following the report, the President and CEO of the American Red Cross, Gail J.

McGovern, released the following statement:

"I am disappointed, once again, by the lack of balance, context and accuracy in the most recent reporting by ProPublica/NPR, which follows the pattern of all their previous Red Cross stories. It is particularly disappointing to see our work misrepresented considering we answered more than 100 questions in writing and provided an interview with the head of our international programs. 
Despite the most challenging conditions we have faced, including changes in government, lack of land for housing, and civil unrest, our hardworking staff- -90 percent of whom are Haitians - continue to meet the long-term needs of the Haitian people. While the pace of progress is never as fast as we would like, Haiti is better off today than it was five years ago.

I will be the first to admit that not every single one of our projects has been flawless. But whenever there have been issues, we have addressed them immediately. It is fair to call us out when mistakes happen, but the impressions left by the article, that we have wasted most of the donated funds and that we haven't left a lasting positive impact, are simply not true. Therefore, we will continue working in Haiti with our heads held high."

\section{Red Cross Response. Condition: Not Authentic but Accommodating}

Following the report, the American Red Cross released the following statement:

"The Red Cross is disappointed, once again, by the lack of balance, context and accuracy in the most recent reporting by ProPublica/NPR, which follows the pattern of all their previous Red Cross stories. It is particularly disappointing to see the organization's work misrepresented considering more than 100 questions were answered in writing and an interview with the head of our international programs was provided.

But to make certain that all rebuilding efforts in Haiti are up to our high standards, a thorough review of all rebuilding efforts will be undertaken. While we are confident that the described episodes of mismanagement are a few unfortunate exceptions out of countless successful projects, it is important that we get to the bottom of this, and swift action will be taken in any case where it is deemed necessary."

\section{Red Cross Response - Not authentic and not accommodating condition}

Following the report, the American Red Cross released the following statement:

"The Red Cross is disappointed, once again, by the lack of balance, context and accuracy in the most recent reporting by ProPublica/NPR, which follows the pattern of all their previous Red Cross stories. It is particularly disappointing to see the organization's work misrepresented considering more than 100 questions were answered in writing and an interview with the head of our international programs was provided.

Despite facing particularly challenging conditions, including changes in government, lack of land for housing, and civil unrest, the hardworking staff -90 percent of whom are 
Haitians - the American Red Cross continues to meet the long-term needs of the Haitian people. And it is unarguable that our efforts have helped ensure that Haiti is better off today than it was five years ago. Therefore, we will continue working in Haiti unreservedly."

\section{United Airlines - Crisis scenario}

Backlash Erupts After United Passenger Gets Yanked Off Overbooked Plane

Security officials dragged a paying passenger Dr. David Dao off a United Express Flight 3411 from Chicago to Louisville, Kentucky.

As Dr. Dao was yanked out of his seat, screaming, his face hit an armrest during the struggle. He was then dragged, unconscious and with a bloody mouth, down the aisle and off the plane. Passengers filmed the spectacle on their phones and the images - and the outragequickly went viral.

The doctor was dragged off the plane because he refused to give up his seat. United wanted to bump four passengers on United Express Flight 3411 from O’Hare International Airport to Louisville, Kentucky. The stated goal was to make room for four United employees. The airline offered compensation of $\$ 400$ in flight vouchers then doubled it, but there were no takers, reportedly because it was the last flight of the day. Four passengers were selected to be involuntarily bumped.

Three complied, but the fourth, Dr. David Dao of Louisville, refused, saying he had to be at work at the hospital the next day. 
United Airlines Response. Condition: Authentic and Accommodating

Following the situation and very strong criticism from passengers all around the world,

United Airlines CEO Oscar Munoz sent out the following statement:

"The truly horrific event that occurred on this flight has elicited many responses from all of us: outrage, anger, and disappointment. I share all of those sentiments, and one above all: my deepest apologies for what happened.

Like you, I continue to be disturbed by what happened on this flight and I deeply apologize to Dr. Dao and to all the customers aboard. No one should ever be mistreated this way.

I want you to know that we take full responsibility and we will work to make it right.

It's never too late to do the right thing. Therefore, I am reaching out to this passenger to talk directly to him and further address and resolve this situation.

I have committed to our customers and our employees that we are going to fix what's broken, so this never happens again. This will include a thorough review of crew movement, our policies for incentivizing volunteers in these situations, how we handle oversold situations and an examination of how we partner with airport authorities and local law enforcement. We'll communicate the results of our review by April 30th.

I promise you we will do better.

-Oscar Munoz, CEO, United Airlines"

United Airlines Response. Condition: Authentic and not Accommodating

Following the situation and very strong criticism from passengers all around the world,

United Airlines CEO Oscar Munoz sent out the following statement:

"The truly horrific event that occurred on this flight has elicited many responses from all of us: outrage, anger, and disappointment. I share all of those sentiments, and one above all: sympathy for Dr. Dao, 
Like you, I continue to be disturbed by what happened on this flight and I deeply apologize Dr. Dao and to all the customers aboard. No one should ever be mistreated this way.

We are still trying to get an overview of what exactly happened but are confident in our processes and procedures we have in place as we go forward

-Oscar Munoz, CEO, United Airlines"

United Airlines Response. Condition: Not Authentic but Accommodating

Following the situation and very strong criticism from passengers all around the world,

United Airlines CEO Oscar Munoz sent out the following statement:

"Regarding the event Sunday, April 9 on United Express Flight 3411, I apologize for having to re-accommodate the customer in question.

Our preliminary report shows that the situation was unfortunately compounded when one of the passengers we politely asked to deplane refused and it became necessary to contact Chicago Aviation Security Officers to help. Our employees followed established procedures for dealing with situations like this.

While the facts and circumstances are still evolving, especially with respect to why this customer defied Chicago Aviation Security Officers the way he did, our team is moving with a sense of urgency to work with the authorities and conduct our own detailed review of what happened.

We are reaching out to this passenger to talk directly to him and further address and resolve this situation.

Furthermore, steps will be taken to make sure that this never happens again. These will include a thorough review of crew movement, our policies for incentivizing volunteers in these situations, how we handle oversold situations and an examination of how we partner with airport authorities and local law enforcement. We'll communicate the results of our review by April 30th.

-Oscar Munoz, CEO, United Airlines" 
United Airlines Response. Condition: Not Authentic and not Accommodating

Following the situation and very strong criticism from passengers all around the world, United Airlines CEO Oscar Munoz sent out the following statement:

"Regarding the event Sunday, April 9 on United Express Flight 3411:

Our preliminary report shows that the situation was unfortunately compounded when one of the passengers we politely asked to deplane refused and it became necessary to contact Chicago Aviation Security Officers to help. Our employees followed established procedures for dealing with situations like this.

While the facts and circumstances of the situation are still evolving, especially with respect to why the customer defied Chicago Aviation Security Officers the way he did, we will refrain from any further comments.

-Oscar Munoz, CEO, United Airlines" 


\section{APPENDIX B - SCALES}

To evaluate authenticity, the participants indicated on a seven-point scale the degree they agreed of disagreed with the each of the following statements:

Shen and Kim's (2012) scale for authenticity:

1. This organization always tells the truth.

2. I believe that this organization's actions are genuine.

3. I feel that this organization is willing to admit to mistakes when they are made.

4. I feel that this organization accepts and learns from mistakes.

5. I believe that this organization's behavior matches its core values.

6. The organization's beliefs and actions are consistent.

7. I think this organization matches the rhetoric with its action.

Molleda and Jain's (2013) scale for authenticity

1. The organization's messages are original.

2. I feel what the organization said was authentic.

3. The organization demonstrated sincere support for the cause

\section{Accommodation}

To evaluate the degree of accommodation in the responses, the participants indicated on a seven-point scale how willing they thought the organization in question would be to do the following: degree they agreed of disagreed with the each of the following statements:

1. To yield to the public's demands.

2. To agree to follow what the public proposed.

3. To accept the publics' propositions.

4. To agree with the public on future action or procedure.

5. To agree to try the solutions suggested by the public.

\section{Crisis responsibility attribution}

To evaluate the crisis responsibility attribution, the participants indicated on a sevenpoint scale the degree they agreed or disagreed with the each of the following statements:

1. Circumstances, not the organization, are responsible for the crisis. 
2. The blame for the crisis lies with the organization. (Reverse coded).

3. The blame for the crisis lies in the circumstances, not the organization.

\section{Organizational reputation}

To evaluate the organizational reputation, the participants indicated on a seven-point scale the degree they agreed or disagreed with the each of the following statements

1. The organization is concerned with the well-being of its publics'.

2. The organization is basically dishonest.

3. I do not trust the organization to tell the truth about the incident.

4. Under most circumstances, I would be likely to believe what the organization says.

5. The organization is NOT concerned with the well-being of its publics

Anger

To measure the degree of anger towards the organization, the participants indicated on a seven-point scale the degree they agreed or disagreed with the each of the following statements:

1. I feel annoyed toward the organization for what happened.

2. I do NOT feel angry toward the organization.

3. Because of the incident, I feel angry at the organization.

Word-of-mouth intention

To evaluate word-of-mouth intention, the participants indicated on a seven-point Likerttype scale how likely they were to do each of the following.

1. I would encourage family members or relatives to support this organization.

2. I would encourage friends to support this organization.

3. I would recommend supporting this organization to someone who asked my advice.

4. I would say positive things about this organization to other people. 


\section{APPENDIX C - MAIN STUDY INSTRUMENT}

\section{Consent Form / Page 1}

This is a research study. The purpose of this survey is to explore how people perceive different types of communication from organizations dealing with crises. Your participation should take no longer than 15 minutes. In order to participate in this study, you must be 18 years of age or older.

Potential Risks or Discomforts: There are no risks or discomforts associated with your participation in this research project.

Compensation: For your time, you will be compensated by Qualtrics for completing this survey.

Benefits: Beyond receiving compensation, you will not benefit directly from your participation in this study.

Confidentiality: Your responses to all questions will be anonymous.

Contact Information: If you have any questions, comments, or needs pertaining to this research project please contact Mikkel Soelberg Christensen (Mikkel.christensen@mail.missouri.edu). If you've any questions or concerns regarding this study and would like to talk to someone other than the researchers, contact MU Campus Institutional Review Board (phone: 573-882-3181, email irb@missouri.edu).

Voluntary Participation: Your participation is entirely voluntary and by not participating you will not be denied anything you are entitled to. You may exit out of the survey program at any point in time.

By continuing the survey, you are giving your informed consent to participate, and you are stating that you are at least 18 years of age. If you wish to participate please click next. If you do not give your consent to participate or you are under 18 please exit out of this window.

Thanks,

Page 2 (Text in brackets did not appear on the actual survey)

This survey presents two different crisis scenarios and the responses from the involved organizations. The scenarios are based on real events, but some key details have been modified. The crisis responses are all made up for research purposes.

To ensure you have read the news stories presented in the survey, simple factual questions about them are included as attention checks. Failure to answer these correctly will end the survey.

In this survey, I will read the presented scenarios and give my best answers.

- Yes

- No 
(If "Yes" proceed to survey, if "No" skip to end of study.)

Page 3

(One of the Red Cross or United Airlines scenarios is randomly selected to be displayed followed by a randomly selected authentic/not authentic * accommodative/advocative crisis response. The participants are not being told what type of response they are seeing.)

How would you describe the response from the CEO? (Open-ended question.)

Based on the case and the response, how much do you agree or disagree with the following statements?

(Strongly agree $1-2-3-4-5-6-7$ Strongly disagree.)

(Crisis Responsibility Attribution)

- Circumstances, not the organization, are responsible for the crisis.

- The blame for the crisis lies with the organization.

- The blame for the crisis lies in the circumstances, not the organization.

(Organizational Reputation)

- The organization is concerned with the well-being of its publics'.

- The organization is basically dishonest.

- I do not trust the organization to tell the truth about the incident.

- Under most circumstances, I would be likely to believe what the organization says.

- The organization is NOT concerned with the well-being of its publics.

(Anger)

- I feel annoyed toward the organization for what happened.

- I do NOT feel angry toward the organization.

- Because of the incident, I feel angry at the organization. 
Based on the response, how likely would you be to talk about the organization?

(Extremely likely $1-2-3-4-5-6-7$ extremely unlikely)

(Word of Mouth Intention)

- I would encourage family members or relatives to support this organization.

- I would encourage friends to support this organization.

- I would recommend supporting this organization to someone who asked my advice.

- I would say positive things about this organization to other people.

- This is an attention check. Please select "Extremely unlikely" for this answer.

$\circ$ (If the participant failed the attention check, it would skip to the end of the survey)

\section{Page 4}

(The scenario that was not displayed on page 3, is displayed here. So, if the Red Cross scenario was displayed on page 3, the United Airlines is now on page 4, and vice versa. Again, it is followed by a randomly selected authentic/not authentic * accommodative/advocative crisis response. The questions from page 3 are repeated on page 4.)

\section{Page 5}

What is the highest level of school you have completed or the highest degree you have received?

- Less than high school degree

- High school graduate (high school diploma or equivalent including GED)

- Some college but no degree

- Associate degree in college (2-year)

- Bachelor's degree in college (4-year)

- Master's degree

- Doctoral degree

- Professional degree (JD, MD)

Please indicate which of the following best describes you.

- White, non-Hispanic

- Hispanic

- African-American

- Asian/Pacific Islander

- Native American 
- Refuse to answer

Information about income is very important to understand. Would you please give your best guess? Please indicate the answer that includes your entire household income in (previous year) before taxes.

- Less than $\$ 10,000$

- $\$ 10,000$ to $\$ 19,999$

- $\$ 20,000$ to $\$ 29,999$

- $\$ 30,000$ to $\$ 39,999$

- $\$ 40,000$ to $\$ 49,999$

- $\$ 50,000$ to $\$ 59,999$

- $\$ 60,000$ to $\$ 69,999$

- $\$ 70,000$ to $\$ 79,999$

- $\$ 80,000$ to $\$ 89,999$

- $\$ 90,000$ to $\$ 99,999$

- $\$ 100,000$ to $\$ 149,999$

- $\$ 150,000$ or more

\section{Page 6}

\section{Debriefing}

Thank you for your time! The stories in question are all based on real events, but some details have been moderated and the organizations' crisis responses were all made up for research purposes. The fabrications are made to test hypotheses about the effectiveness of certain types of crisis communication. If you have questions and/or you wish to withdraw your data from the study, please email the primary investigator Mikkel Christensen at mikkel.christensen@mail.missouri.edu 


\section{VITA}

Mikkel Soelberg Christensen was born December 14, 1984 in Odder, Denmark. He did his undergraduate work at the Danish School of Media and Journalism in Aarhus, Denmark, and graduated in 2010 with a B. A, in broadcast journalism. He earned an M.A. in political science from University of Missouri in 2012, and he completed his Ph.D. in Journalism at the University of Missouri in 2019.

Since August 2017, Mikkel has been an assistant professor of strategic communication in the School of Design at Stephens College, where he has taught classes on public relations, journalism, and media literacy, while finishing his Ph.D. In August 2019, he will join the College of Communication at Butler University as an assistant professor in strategic communication.

His research interests include public relations, political communication, and crisis communication. 